\title{
LA PRODUCCIÓN Y EL FLUJO DEL CONOCIMIENTO EN LA CARRERA INTERNACIONAL POR LAS VACUNAS DE COVID-19
}

\author{
THE PRODUCTION AND FLOW OF KNOWLEDGE IN THE \\ INTERNATIONAL RACE FOR COVID-19 VACCINES
}

\author{
LA PRODUCTION ET LA CIRCULATION DES \\ CONNAISSANCES DANS LA COURSE INTERNATIONALE \\ DES VACCINS DE COVID-19
}

\author{
NAin MarTínez \\ El Colegio de México \\ nain.martinez@colmex.mx
}

\begin{abstract}
Resumen: En este artículo se rastrea, desde la perspectiva de los estudios de ciencia y tecnología, la carrera internacional por las vacunas de covid-19 y se examinan los aspectos epistemológicos, organizativos, de regulación y financieros que posibilitaron su desarrollo. La producción y el flujo de conocimiento fue clave en la gestión de la covid-19. El impacto de la pandemia generó las condiciones para el rápido avance de la investigación y movilizó el ecosistema global de innovación biomédica. La competencia internacional por el control de las vacunas moldeó el desarrollo de los proyectos, mientras que las variaciones domésticas en la autonomía de las instancias reguladoras y la actuación de la comunidad científica delinearon el escrutinio público y los procesos de autorización. Se argumenta que la interacción entre la arena política y el desarrollo tecnocientífico configuró las opciones disponibles para la inmunización internacional y las controversias sobre seguridad, efectividad y justicia que han enmarcado su distribución y acceso.
\end{abstract}

Palabras clave: Covid-19; vacunas; política del conocimiento;

gobernanza de la salud; nacionalismo de las vacunas.

ABstract: This article employs the perspective of science and technology studies to follow the course of the international race for covid-19 vaccines, examining the epistemological, organizational, regulatory and financial aspects that enabled their development. The production and flow of knowledge 
was key in the response to covid-19. The impact of the pandemic enabled the conditions for rapid advances in research and mobilized the global ecosystem of biomedical innovation. International competition for control of the vaccines shaped project development, while domestic differences in the autonomy of the regulatory bodies and the actions of the scientific community determined the public scrutiny and authorization processes. It is argued that the interaction between the public sphere and technical and scientific development configured the available options for international immunization and the controversies around security, effectiveness and justice that have framed vaccine distribution and access.

Keywords: covid-19; vaccines; knowledge policy; health governance; vaccine nationalism.

\section{Traducción de Fionn Petch, cm Idiomas}

RÉsumÉ: Cet article retrace, du point de vue des études scientifiques et technologiques, la course internationale aux vaccins covid-19 et examine les aspects épistémologiques, organisationnels, réglementaires et financiers qui ont rendu leur développement possible. La production et la circulation des connaissances ont été essentielles dans la gestion de la covid-19. L'impact de la pandémie a créé les conditions d'une avancée rapide de la recherche et mobilisé l'écosystème mondial de l'innovation biomédicale. La concurrence internationale pour le contrôle des vaccins a façonné le développement des projets, tandis que les variations nationales dans l'autonomie des organismes de réglementation et les performances de la communauté scientifique ont façonné les processus d'examen du public et d'autorisation. Il est avancé que l'interaction entre l'arène politique et le développement techno-scientifique a façonné les options disponibles pour la vaccination internationale et les controverses sur la sécurité, l'efficacité et la justice qui ont encadré sa distribution et son accès.

Mots-clés : covid-19 ; vaccins; politique de la connaissance;

gouvernance de la santé; nationalisme vaccinal.

Traducción de Rafael Segovia, cm Idiomas

Fecha de recepción: junio de 2021

Fecha de aceptación: octubre de 2021 


\section{INTRODUCCIÓN}

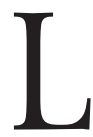

a carrera por las vacunas de COVID-19 representa el mayor despliegue tecnocientífico en la última generación y adquirió una relevancia social con escasos precedentes. A finales de 2019, la cepa de coronavirus SARs-Cov-2 que causa el covid-19 no había sido identificada ni estudiada, simplemente se desconocía su existencia. No obstante, para enero de 2021 se distribuían las vacunas de Pfizer/BioNTech, Moderna, Sputnik V, CanSino, Sinovac y AstraZeneca/Oxford. ${ }^{1}$ Investigaciones previas han analizado las agendas de gobiernos y actores políticos en torno a las vacunas, ${ }^{2}$ pero la relación de éstas con el proceso de investigación y desarrollo $(\mathrm{I}+\mathrm{D})$ ha recibido menor atención.

Los efectos sanitarios y económicos de la pandemia de COVID -19 configuraron una problemática global e interdependiente, cuyas características hacían necesaria la cooperación internacional. ${ }^{3}$ En cambio, Estados Unidos (EE.UU.), China, Rusia, Alemania, el Reino Unido (RU) y Francia rivalizaron por el desarrollo y el control de las vacunas. ${ }^{4}$ Otros, como la India, Japón, Australia y Canadá, promovieron proyectos nacionales, reivindicaron la soberanía sobre la restringida capacidad global para la manufactura de vacunas y

${ }^{1}$ University of Oxford y Global Change Data Lab, "Coronavirus (COvid-19) Vaccinations”, Our World in Data, https://ourworldinda ta.org/ covid-vaccinations (consulta del 19 de febrero de 2021).

2 Véanse Ana Santos Rutschman, "The reemergence of vaccine nationalism", Georgetown Journal of International Affairs, 2020 (en preprensa); David P. Fidler, "Vaccine nationalism's politics", Science, 369 (2020), p. 749; Shinu Kuriakose, "Global health: Global health diplomacy", Journal of Global Health, 10 (2020), 020354; Thomas J. Bollyky y Chad P. Bown, "The tragedy of vaccine nationalism: Only cooperation can end the pandemic", Foreign Affairs, 99 (2020), pp. 96-108.

3 Tana Johnson, "Ordinary Patterns in an Extraordinary Crisis: How International Relations Makes Sense of the Covid-19 Pandemic", International Organization, 74 (2020), pp. 148-168.

${ }^{4}$ Santos Rutschman, art. cit. 
realizaron acuerdos de compra anticipada (ACA) en perjuicio de la distribución internacional. ${ }^{5}$ En contraste, la Plataforma de Acceso Global a las Vacunas de covid-19 (covax) de la Organización Mundial de la Salud (oms) recibió respaldo político y financiero limitado, en particular, de actores clave como Ee.uU., China y Rusia. ${ }^{6}$

Los estudios en relaciones internacionales (RI) y de salud global han mostrado que la política de las vacunas de COVID-19 se enmarca en tendencias estructurales como la erosión del multilateralismo, la fragmentación internacional, la competencia tecnológica global y las tensiones geopolíticas entre EE.UU. y China. ${ }^{7}$ La pandemia acentuó la polarización, el control de fronteras y la xenofobia, lo que causó disputas diplomáticas y la revitalización de los nacionalismos. Para los gobiernos, los proyectos de vacuna canalizaron las demandas domésticas de solución y constituyeron un medio para levantar la moral de la población, mostrar su capacidad frente a rivales internos y externos, y acrecentar la influencia internacional. ${ }^{8}$ La inmunización se erigió como la principal estrategia para la gestión sanitaria, por lo que el acceso a las vacunas tiene implicaciones para la

${ }^{5}$ Oxfam International " Small group of rich nations have bought up more than half the future supply of leading CoviD-19 vaccine contenders", 17 de septiembre de 2020, https://www.oxfam.org/en/press-releases/ small-group-rich-nations-have-bought-more-half-future-supply-leadingcovid-19 (consulta del 14 de septiembre de 2021); Marco Hafner, Erez Yerushalmi, Clement Fays, Eliane Dufresne y Christian Van Stolk, CovID-19 and the cost of vaccine nationalism, Santa Monica, RAND Corporation, 2020.

6 "Whoever Finds the Vaccine Must Share It": Strengthening Human Rights and Transparency Around COVID-19 Vaccines", Human Rights Watch, 2020; Oxfam International, art. cit.

7 Kathleen R. McNamara y Abraham L. Newman, "The Big Reveal: COvID-19 and Globalization's Great Transformations”, International Organization, 74 (2020), pp. 59-77.

${ }^{8}$ Santos Rutschman, art. cit; François Heisbourg, "From Wuhan to the world: How the pandemic will Reshape Geopolitics", Survival, 62 (2020), pp. 7-24. 
aprobación de los gobiernos y la reorganización de la economía global. ${ }^{9}$

No obstante, la contribución relevante de las investigaciones en RI y en campos afines sobre el tema, algunas áreas exigen mayor elaboración. Dicha literatura analiza, desde modelos de elección racional, la actuación de gobiernos y actores políticos en la gestión de la pandemia de COVID-19 y sus agendas en el desarrollo de las vacunas, ${ }^{10}$ pero ofrece un reporte limitado sobre el papel del conocimiento en el proceso político y el efecto de las agendas políticas en la I+D. ${ }^{11}$ Esta investigación contribuye a tales cuestiones desde el trabajo de frontera en política internacional y los estudios de ciencia y tecnología (sTs, por sus siglas en inglés).

Los enfoques tradicionales en RI tienden a tratar la I+D como una arena exógena, secundaria, neutral o instrumental. ${ }^{12}$ Por otro lado, el enfoque constructivista ha iluminado, por ejemplo, el papel normativo de los marcos de entendimiento (es decir, los conceptos y el encuadre de los problemas) y la influencia del conocimiento en la política internacional; sin embargo, estos estudios se suscriben, en gran medida, a las dinámicas institucionales y las redes de actores transnacionales vinculadas con estos procesos. ${ }^{13}$

9 T. Bollyky y C. Bown, art. cit.; Fidler, "Vaccine nationalism...", art. cit.

10 Tanisha M. Fazal, "Health diplomacy in pandemical times", International Organization, 74 (2020), pp. E78-E97.

11 Planteamiento propio con base en la revisión de la literatura. Algunas reflexiones sobre la relevancia de profundizar en el papel del conocimiento y los expertos en la investigación en RI pueden consultarse en T. Johnson, op. cit.; Phillip Y. Lipscy, "Covid-19 and the Politics of Crisis", International Organization, 74 (2020), pp. E98-E127.

12 Matthias Leese y Marijin Hoijtink, "How (not) to talk about technology: international relations and the question of agency", en Hoijtink y Leese (eds.), Technology and agency in international relations, Routledge, 2019, pp. 1-23; Maximilian Mayer, Mariana Carpes y Ruth Knoblich (eds.), The Global Politics of Science and Technology, Springer-Verlag, 2014, pp. 1-35.

13 Amandine Orsini et al., "Boundary concepts for boundary work between science and technology studies and international rela- 
Por ello, los STs aportan una perspectiva complementaria sobre los sitios y formas de interacción entre la carrera internacional por las vacunas y la $\mathrm{I}+\mathrm{D} .{ }^{14}$

El trabajo en sTs ha mostrado que la política global de la investigación biomédica y el desarrollo farmacológico es un dominio que se dirime en la intersección de regulaciones, agendas de investigación, intereses comerciales, compuestos bioquímicos y necesidades médicas. ${ }^{15}$ La producción de conocimiento enmarca la manera en que gobiernos, organismos multilaterales, empresas y grupos sociales definen las prioridades e interpretan los riesgos de la $\mathrm{I}+\mathrm{D}$, lo cual puede derivar en, por ejemplo, agendas que priorizan el control del conocimiento sobre el uso biomédico. ${ }^{16}$ Las decisiones de carácter técnico, como la redefinición de la evidencia clínica, pueden transformar la industria farmacéutica global y las regulaciones que median su relación con sujetos humanos para derivar en nuevas formas de asimetría entre geografías y grupos sociales. ${ }^{17}$ En las comunidades políticas existen variaciones en la manera en la que se incorporan la experiencia y el conocimiento en las decisiones públicas y en el escrutinio social sobre las agendas de I+D. ${ }^{18}$ Además,

tions: Special issue introduction", Review of Policy Research, 34 (2017), pp. 734-743.

${ }^{14}$ Rolf Lidskog y Göran Sundqvist, "When does science matter? International relations meets science and technology studies", Global Environmental Politics, 15 (2015), pp. 1-20; Claudia Aradau y Jef Huysmans, "Critical methods in International Relations: The politics of techniques, devices and acts", European Journal of International Relations, 20 (2004), pp. 596-619.

${ }^{15}$ Andrew Lakoff, "The Right Patients for the Drug: Pharmaceutical Circuits and the Codification of Illness", en Edward J. Hackett, Olga Amsterdamska, Michael Lynch y Judy Wajcman (eds.), The handbook of science and technology studies, Cambridge, The MIт Press, 2008, pp. 741-759.

${ }^{16}$ Philip R. Egert y Barbara L. Allen, "Knowledge justice: an opportunity for counter-expertise in security vs. science debates", Science as Culture, 28 (2017), pp. 351-374.

${ }^{17}$ Adriana Petryna, When experiments travel: clinical trials and the global search for human subjects, Princeton, University Press, 2009.

${ }^{18}$ Sheila Jasanoff, The Fifth Branch. Science Advisers as Policymakers, Cambridge, Harvard University Press, 1990. 
los actores no sólo utilizan o capturan los beneficios de la innovación, sino que pueden influir en el contexto y las decisiones que moldean las trayectorias de desarrollo y, por consiguiente, en las cualidades de los fármacos resultantes. ${ }^{19}$

Este artículo examina el desarrollo sociotécnico ${ }^{20}$ de la carrera por las vacunas de COVID-19. En las primeras dos secciones se aporta una revisión de antecedentes y se elabora un marco analítico desde la perspectiva de los sts. Después, se rastrea la trayectoria de desarrollo en cinco momentos: $i$ ) la identificación del sARs-Cov-2; ii) su propagación internacional; iii) la formación de las estrategias para la producción de vacunas en EE.UU. y China; $i v$ ) la competencia internacional y, v) el proceso de autorización de las vacunas. En cada etapa se analiza la relación entre la arena sociopolítica y la $\mathrm{I}+\mathrm{D}$, identificando los principales aspectos epistemológicos, organizativos, de regulación y financieros que posibilitaron y dieron forma a los proyectos. Posteriormente, se discute el arreglo sociotécnico de las siete vacunas en las que se concentra la distribución internacional. Con lo anterior, este estudio extiende la discusión sobre la carrera por las vacunas a su dimensión epistémica, y contribuye a la comprensión de las controversias sobre seguridad, efectividad y justicia que han delineado el desarrollo y el acceso global a las vacunas.

\section{EL CONOCIMIENTO EN LA POLÍTICA EPIDEMIOLÓGICA INTERNACIONAL}

El intercambio de conocimiento normado por el Reglamento Sanitario Internacional (RSI) es esencial para la gobernanza de enfermedades infecciosas. Aunque este aspecto ha recibido menor atención, el arreglo de normas, flujos de in-

${ }^{19}$ Steven Epstein, Impure science: AIDS, activism, and the politics of knowledge, Berkeley, University of California Press, 1996.

${ }^{20}$ Los aspectos técnicos y sociales que moldean las trayectorias de $\mathrm{I}+\mathrm{D}$ y sus resultados. 
formación y actores revela cuestiones fundamentales sobre la dinámica política que delineó la identificación y el manejo de la Covid-19. En 1951, la Asamblea Mundial de la Salud adoptó el RSI como un instrumento vinculante para la gestión transnacional de enfermedades. El reglamento estipulaba: $i$ ) la creación de un listado de enfermedades de interés internacional (la peste, la viruela, la cólera, el tifus, la fiebre recurrente y la fiebre amarilla); ii) la obligatoriedad de la notificación de los Estados miembros de los casos de estas enfermedades, y iii) el establecimiento de mecanismos de control en cruces fronterizos, como la expedición y el requerimiento de certificados médicos y de vacunación. ${ }^{21}$ De esta manera, el funcionamiento del RSI precisaba de la generación y el intercambio de información entre las partes. En las siguientes décadas, los cambios en la agenda sanitaria internacional, en sus actores y en las enfermedades de interés, como el ébola y el VIH, generaron controversias sobre el limitado alcance del Rsi. Sin embargo, ese arreglo se mantuvo en gran medida hasta la reforma de 2005.

En noviembre de 2002 se detectó el primer caso del Síndrome Respiratorio Agudo Grave (sARs, por sus siglas en inglés) en China, pero el brote fue notificado a la oms hasta febrero de 2003, cuando la propagación alcanzó a Hong Kong. ${ }^{22}$ La oms coordinó la acción internacional y se convirtió en depositaria de la información epidemiológica. No obstante, el Rsi no preveía epidemias emergentes, como era el caso del sars, y China se negó a aportar información de manera voluntaria. En el contexto de la guerra contra el terrorismo, en EE.UU. la crisis sanitaria se tradujo como una amenaza de seguridad nacional asociada con el bioterroris-

${ }^{21}$ Lawrence Gostin, "International infectious disease law: revision of the World Health Organization's International Health Regulations”, JAMA, 291 (2004), pp. 2623-2627.

${ }^{22}$ Loc. cit.; Simon Carvalho y Mark Zacher, "The International Health Regulations in Historical Perspective”, en Andrew Price-Smith (ed.), Plagues and politics: infectious disease and international policy, Londres, Palgrave Macmillan, 2001, pp. 235-261. 
mo. A nivel interno, la securitización de esta agenda generó una política de financiamiento de investigación que limitó la difusión de resultados de interés médico que pudieran traducirse en un riesgo de bioseguridad y, a nivel diplomático, promovió la importancia de un sistema global para la vigilancia de riesgos sanitarios. ${ }^{23}$ En China, los impactos económico y político del sARs posicionaron la agenda sanitaria entre las prioridades diplomáticas y el Ejército Popular de Liberación se involucró de manera más activa en la I+D de patógenos y en el control del conocimiento en el área. ${ }^{24}$

Como resultado, se inició un proceso de reforma del RSI que replanteó el alcance y la naturaleza del intercambio de conocimiento. ${ }^{25}$ El nuevo RSI, aprobado por la Asamblea Mundial de la Salud en 2005, introdujo el concepto de "emergencia de salud pública de importancia internacional" (PHeic, por sus siglas en inglés), el cual extendía las obligaciones de información a cualquier evento o riesgo sanitario de interés transnacional, incluyendo enfermedades emergentes, bioterrorismo, catástrofes naturales y desastres ambientales. ${ }^{26}$ La reforma también comprometía a las partes a construir sistemas nacionales de vigilancia y control activo de riesgos sanitarios. Los cambios incluían un sistema más claro para el intercambio de muestras biológicas de patógenos y posibilitaba por primera vez que la oms utilizara fuentes no estatales para la identificación y el

23 P. Egert y B. Allen, art. cit.

24 Lyle Fearnley, "Viral Sovereignty or Sequence Etiquette? Asian Science, Open Data, and Knowledge Control in Global Virus Surveillance”, East Asian Science, Technology and Society: An International Journal, 14 (2020), pp. 479-505.

25 La Asamblea Mundial de la Salud adoptó los cambios al Rsi en 2005, entrando en vigor en 2007. Véase wHo, International Health Regulations (2005), tercera edición, wHO, 2016.

26 Andrew Lakoff, "Global health security and the pathogenic imaginary”, en Sheila Jasanoff y Sang-Hyun Kim (eds.), Dreamscapes of modernity: Sociotechnical imaginaries and the fabrication of power, Chicago, University of Chicago Press, 2015, pp. 300-320. 
seguimiento de riesgos sanitarios (p. ej., medios digitales, sociedad civil). ${ }^{27}$

No obstante el avance internacional en torno al RSI, Indonesia detuvo el intercambio de patógenos con la oms a finales del 2006. El gobierno identificó que una muestra aportada de $\mathrm{H} 5 \mathrm{~N} 1$ había sido compartida con una farmacéutica australiana para el desarrollo de una vacuna cuyo costo restringía el acceso a su mercado. Con base en el Convenio sobre la Diversidad Biológica (CBD), ${ }^{28}$ Indonesia reivindicó la soberanía sobre los patógenos aislados en su jurisdicción y el derecho a participar en los beneficios derivados de la I+D. ${ }^{29}$ La "soberanía viral", con distintos matices, fue retomada en países como China, Vietnam, Corea del Sur, Arabia Saudita y Brasil, ${ }^{30}$ lo cual llevaría a la negociación del Marco de Preparación para una Gripe Pandémica. ${ }^{31}$

El nuevo arreglo normativo del Rsi se implementó en la epidemia de Hin 1 en 2009. México notificó la detección del virus a la oms y mantuvo un reporte detallado sobre su pro-

27 Jeremy Youde, "MERS and global health governance", International Journal, 70 (2015), pp. 119-136.

${ }^{28}$ El CBD reconoce la soberanía de los Estados sobre sus recursos biológicos y el derecho de los países en desarrollo a participar en los beneficios derivados de sus recursos genéticos. En este marco, el Protocolo de Nagoya (2010) estableció las obligaciones de acceso a los recursos genéticos y la distribución de sus beneficios.

${ }^{29}$ Fidler, "Vaccine nationalism...", art. cit.

${ }^{30}$ Michelle Rourke, "Restricting access to pathogen samples and epidemiological data: a not-so-brief history of 'viral sovereignty' and the mark it left on the world", en Mark Eccleston-Turner y Iain Brassington (eds.), Infectious Diseases in the New Millennium, Springer, 2020, pp. 167-191.

${ }^{31}$ La controversia llevó a la adopción del Marco de Preparación para una Gripe Pandémica (2011) para el acceso a virus de influenza con potencial pandémico y la distribución de los derivados de su I+D, basado en el registro de los intercambios de material biológico y el establecimiento de contratos que comprometen a los desarrolladores a compartir los productos con la oms para su distribución internacional (Acuerdo estándar de transferencia de material 2). Véase wHO, Pandemic influenza preparedness framework for the sharing of influenza viruses and access to vaccines and other benefits, Francia, wHo, 2011. 
pagación. Los datos iniciales indicaban una alta transmisibilidad y virulencia y, el 25 de abril de ese año, la oms realizó la declaratoria de PHeic. Entre mayo y junio, EE.UU., el RU, Francia y Alemania realizaron ACA con las farmacéuticas que trabajaban en el desarrollo de vacunas y el acaparamiento restringió su acceso en el Sur global. Sin embargo, para julio, los estudios mostraban una baja tasa de mortalidad. La oMs fue criticada por la costosa declaratoria de PHEIc; en Francia, surgió una polémica sobre el gasto gubernamental en las vacunas "innecesarias"; 32 en México, el impacto económico y las críticas a una actuación percibida como "desproporcionada" afectaron el desempeño electoral del partido en el gobierno. ${ }^{33}$

Como consecuencia, la epidemia de HiN 1 expuso las tensiones entre la gestión precautoria de riesgos sanitarios potenciales y las costosas decisiones que los gobiernos y la oms debían tomar con información limitada. ${ }^{34} \mathrm{El}$ caso también configuró un precedente en el acaparamiento de vacunas y mostró los riesgos financieros del desarrollo de fármacos con una rentabilidad incierta. ${ }^{35}$ Después, en 2012, la epidemia del Síndrome Respiratorio de Oriente Medio (MERs) exhibió la reticencia de los gobiernos a compartir información sobre su propagación y las muestras biológicas del virus, y en el brote de ébola (2014) se criticó la demora de la oms en la declaratoria de PHEIc. ${ }^{36}$

Los antecedentes muestran que en el Norte y el Sur global han surgido diversas formas de control y soberanía del co-

${ }^{32}$ Lakoff, "Global health...", art. cit.

33 Emilio Gutiérrez, Jaakko Meriläinen y Adrian Rubli, "Electoral repercussions of a pandemic: evidence from the $2009 \mathrm{H}_{1} \mathrm{~N}_{1}$ Outbreak", SSRN (2021), en preprensa.

${ }^{34}$ Lakoff, "Global health...", art. cit.; J. Youde, op. cit.

35 Fazal, art. cit.

36 David Fidler, "Global health diplomacy and the Ebola outbreak", en Sam F. Halabi, Lawrence O. Gostin y Jeffrey S. Crowley (eds.), Global Management of Infectious Disease After Ebola, Oxford, University Press, 2017, pp. 133-148. 
nocimiento de interés para la gestión epidemiológica y el desarrollo biomédico. Paradójicamente, la degradación ambiental y la interconectividad mundial han incrementado la frecuencia en el surgimiento de enfermedades emergentes y su capacidad de propagación, lo cual se traduce en una mayor complejidad para la acción multilateral. El marco de vigilancia y control precautorio del RSI requiere del desarrollo de capacidades técnicas en algunas geografías con recursos limitados y, como lo evidencian las controversias en torno a su implementación, produce incertidumbre en la toma de decisiones que puede generar costos políticos y económicos significativos. Además, el arreglo de las normas de identificación, intercambio y control de patógenos como un bien público global se encuentra en tensión con el desarrollo de bienes biomédicos y las normas internacionales de propiedad intelectual que regulan su distribución y acceso diferenciado. Este aspecto se aborda con mayor detalle en el siguiente apartado.

\section{LA POLÍTICA DEL DESARROLLO FARMACOLÓGICO}

El trabajo en STs ha examinado la interacción entre el entorno sociopolítico y la I+D. Desde el determinismo tecnocientífico se explica el desarrollo biomédico y farmacológico como el producto del progreso científico y su uso como inherente a los beneficios. En cambio, la investigación en sTs ha demostrado que los fármacos y sus efectos son moldeados por redes heterogéneas de compuestos bioquímicos, pacientes, prácticas clínicas, agendas de investigación, regulaciones, cadenas económicas y geografías. ${ }^{37}$

La configuración del régimen global de I+D (p. ej., la combinación de actores, normas, orientaciones y financiamientos) regula la producción de conocimiento y la disponibilidad

${ }^{37}$ Lakoff, “The Right Patients...”, art. cit. 
de fármacos. ${ }^{38}$ En la posguerra, la innovación biomédica se caracterizó por el financiamiento público, los objetivos de salud pública, la investigación basada en universidades y las restricciones en patentes médicas esenciales. En este entorno se desarrollaron, por ejemplo, las vacunas Salk y Sabin para la poliomielitis, cuyas características (patente libre, alto costo-efectividad, fácil aplicación, entre otras) posibilitaron la implantación de programas internacionales de inmunización. ${ }^{39}$

Entre las décadas de 1980 y 2000, la participación de las grandes farmacéuticas en la I+D aumentó de 30\% a $60 \%$. Los portafolios privados se enfocaron en el desarrollo de tratamientos para padecimientos crónicos como la depresión y la hipertensión, así como de medicamentos para "mejorar el desempeño" (p. ej., Viagra, Adderall), mismos que conllevan una alta rentabilidad por la frecuencia de uso y la demanda en el Norte global. En contraste, la rentabilidad baja o incierta limitó la I+D en enfermedades infeccionas y emergentes. ${ }^{40}$ Para abordar la falla en el mercado, EE.UU. y la Unión Europea (UE), principales financiadores públicos de la I+D en el área biomédica, promovieron la colaboración academia-industria y la protección internacional de patentes. Sin embargo, estas políticas también han favorecido el uso de los recursos y las capacidades de investigación públicas en líneas de desarrollo que por sus características limitan

${ }^{38}$ Loc. cit.; Kelly Ann Joyce, Jennifer E. James y Melanie Jeske, "Regimes of Patienthood: Developing an Intersectional Concept to Theorize Illness Experiences", Engaging Science, Technology, and Society, 6 (2020), pp. 185-192.

${ }^{39}$ Stuart Blume, "Towards a history of 'the vaccine innovation system' 1950-2000", en C. Hannaway (ed.), Biomedicine in the twentieth century: Practices, policies, and politics, Amsterdam, Ios-Press, 2008, pp. 255-286.

${ }^{40}$ Patrice Trouiller, Piero Olliaro, Els Torreele, James Orbinski, Richard Laing y Nathan Ford, "Drug development for neglected diseases: a deficient market and a public-health policy failure", The Lancet, 359 (2002), pp. 2188-2194. 
el beneficio social, ${ }^{41}$ así como el monopolio de medicamentos esenciales. ${ }^{42}$

Los criterios científicos y técnicos incorporados en las regulaciones e instituciones especializadas ejercen un papel de autoridad en el procesamiento del conocimiento. En EE.UU. y el RU, por ejemplo, las instituciones internalizan distintas conceptualizaciones sobre la relación aceptable de beneficioriesgo, las cuales enmarcan los procedimientos de autorización de medicamentos y las decisiones divergentes. ${ }^{43}$ Por otro lado, la forma en que se utiliza el conocimiento en decisiones de interés público (o "epistemologías cívicas") está moldeada por la interacción entre culturas políticas, tradiciones regulatorias, instituciones, ecosistemas de I+D y grupos sociales. Durante la crisis de vir en San Francisco, a través del uso y la producción de conocimiento, los activistas introdujeron cambios en la regulación de la investigación clínica y, de esta manera, reconfiguraron el arreglo normativo y ético de una arena habitada por farmacéuticas y científicos. ${ }^{44}$ En la autorización de fármacos, los reguladores, además de la evidencia empírica, consideran aspectos relativos al contexto como la reputación de la farmacéutica, las necesidades de los pacientes, las alternativas médicas y el interés público. ${ }^{45}$ Las líneas de investigación y la configuración de los fármacos pueden internalizar visiones normativas que se repro-

${ }^{41}$ Por ejemplo, alta especialización y requerimientos técnicos en la producción, distribución y aplicación de tratamientos y medicamentos que restringen su transferencia al Sur global y el acceso a grupos potencialmente beneficiados.

42 Javier Lezaun y Catherine M. Montgomery, "The pharmaceutical commons: Sharing and exclusion in global health drug development", Science, Technology E् Human Values, 40 (2015), pp. 3-29.

${ }^{43}$ John Abraham y Courtney Davis, "Deficits, expectations and paradigms in British and American drug safety assessments: Prising open the black box of regulatory science", Science, technology, E゚ human values, 32 (2007), pp. 399-431.

44 Epstein, op. cit.

${ }^{45}$ Boris Hauray, "From regulatory knowledge to regulatory decisions: the European evaluation of medicines", Minerva, 55 (2017), pp. 187-208. 
ducen en la distribución asimétrica de los beneficios y riesgos asociados a la etapa de desarrollo y su posterior uso. Por ejemplo, como lo evidencia el desarrollo de anticonceptivos mayoritariamente en cuerpos y para el uso de mujeres. Las prioridades en el diseño de los protocolos clínicos (p. ej., parámetros, criterios de selección, implementación) pueden afectar la representatividad social y el análisis de variables relevantes para grupos específicos y, con ello, el grado de incertidumbre aceptable en la relación beneficio-riesgo para algunos sectores, frecuentemente mujeres, minorías étnicas y otros grupos vulnerables. ${ }^{46}$ Muestra de esto fueron los ensayos en la India de una vacuna para el papiloma, durante los cuales se desestimó la evidencia clínica sobre las variaciones locales en el genotipo del virus y la demografía de incidencia, lo que resultó en efectos sanitarios adversos. ${ }^{47}$

Las agendas y perspectivas del contexto influyen las líneas de investigación y las cualidades contingentes de los fármacos, como lo muestra el desarrollo de la vacuna para la hepatitis B. En 1972, el investigador Baruch Blumberg patentó la primera vacuna basada en plasma, trabajo que fue galardonado con el Nobel de Medicina; sin embargo, el desarrollo de la vacuna careció de interés. El padecimiento se asociaba al "Tercer Mundo" y a grupos institucionalmente discriminados -trabajadoras sexuales y gays-. Después, la farmacéutica Merck y la Universidad de California, en San Francisco, produjeron una vacuna experimental de ADN recombinante, pero el proyecto buscaba más un avance tecnológico que tratamiento. No obstante, este coincidió con el interés gubernamental por posicionar a EE.UU. como líder en biotecnología y con el surgimiento local de inversionistas de riesgo, lo cual estimuló su desarrollo. ${ }^{48}$

${ }^{46}$ Laura Briggs, Reproducing empire: Race, sex, science, and US imperialism in Puerto Rico, Berkeley, University of California Press, 2002.

47 Fouzieyha Towghi, "The biopolitics of reproductive technologies beyond the clinic: localizing HPV vaccines in India”, Medical anthropology, 32 (2013), pp. 325-342.

${ }^{48}$ Farah Huzair y Steve Sturdy, "Biotechnology and the transformation of vaccine innovation: The case of the hepatitis $B$ vac- 
El arreglo sociotécnico de los fármacos media su traducción en beneficios para los ambientes y grupos sociales, así como sus significados políticos más amplios. En el caso de la vacuna Merck, la complejidad técnica y el costo (de 240 a 300 dólares) restringían la distribución en el Sur global y el acceso de los grupos con alta incidencia. Paradójicamente, la asociación con grupos discriminados causaba una baja aceptación en otros usuarios potenciales. La vacuna se promovió como una medida preventiva de algunos tipos de cáncer, individualizando el riesgo previamente agregado en grupos y diluyendo su significado sexual. Mientras que el proyecto fue precursor de los fármacos de alto costo para la prevención de riesgos, su acceso en el Sur global requirió el desarrollo de un mercado alterno de vacunas de plasma de bajo costo. ${ }^{49}$

El trabajo en sTs expone el entrelazamiento de la política y el desarrollo tecnocientífico: desde el régimen de I+D hasta el efecto de los fármacos. Enmarcado en esta tradición, este estudio examina el desarrollo sociotécnico de las vacunas de COviD-19 mediante el análisis cualitativo de distintas fuentes documentales primarias y secundarias, entre las que se incluyen bases de datos de proyectos,${ }^{50}$ literatura científica, documentos legales, declaraciones gubernamentales y de las farmacéuticas, archivos de entrevistas y notas de prensa. ${ }^{51}$ A continuación, se presentan los resultados.

cines 1968-2000", Studies in History and Philosophy of Science, 64 (2017), pp. 11-21.

${ }^{49}$ Loc. cit.; Laura Mamoa y Steven Epstein, "The pharmaceuticalization of sexual risk: vaccine development and the new politics of cancer prevention”, Social Science Ẽ Medicine, 101 (2014), pp. 155-165.

${ }^{50}$ Madhumita Shrotri, Tui Swinnen, Beate Kampmann y Edward P. K. Parker, "An interactive website tracking CoviD-19 vaccine development", Lancet Global Health, 9 (2021), pp. 590-592; Jeff Craven, "Covid-19 vaccine tracker", Regulatory Afairs Professionals Society, https://www.raps.org/newsand-article/newsarticles/2020/3/covid-19-vaccine-tracker (consulta del 15 de febrero de 2021).

${ }^{51} \mathrm{El}$ autor realizó la traducción de las citas textuales. 


\section{El DESARROLLO SOCIOTÉCNICO DE LAS VACUNAS}

\section{El SARS-COV-2: control del conocimiento y resistencia}

La actuación de la sociedad civil en la difusión de información y conocimiento medió el funcionamiento del RSI y el seguimiento de la comunidad internacional al brote de CoviD-19. Frente a la inacción y censura en China, la publicación de la secuencia genética del sARs-Cov-2 enmarcó el desarrollo político y posibilitó el surgimiento de los primeros proyectos de vacuna.

En diciembre del 2019, el Hospital Central de Wuhan atendió diversos casos de neumonía atípica; para el día 30 del mismo mes, el médico Li Wenliang recibió los resultados de estudios clínicos que apuntaban a infecciones de sARs. Wenliang compartió los resultados con un grupo de colegas a través de WeChat-aplicación similar a WhatsApp- para advertirles sobre el riesgo, el cual se viralizó en las redes. ${ }^{52}$ Como resultado, al día siguiente, la oficina local de la oms detectó una mención de sARs en los medios y comenzó a indagar sobre el brote. ${ }^{53}$ Las autoridades locales inicialmente lo negaron, pero la oms seguía la propagación en las redes. Las publicaciones sobre la extraña neumonía comenzaron a ser retiradas y las autoridades locales ejercieron acciones de censura contra ciudadanos y medios de comunicación, entre éstos, Wenliang, quien fue amonestado por difundir información falsa para perturbar el orden social. ${ }^{54}$

52 Andrew Green, "Li Wenliang”, The Lancet, 395 (2020), p. 682.

53 WHO, "Listings of WHO's response to COVID-19", 29 de junio 2020, https://www.who.int/news/item/29-06-2020-covidtimeline (consulta del 14 de octubre de 2020).

${ }^{54}$ El 7 de febrero de 2020, Wenliang falleció a los 33 años por coviD-19. Véase Chris Buckley, "Chinese doctor, silenced after warning of outbreak, dies from coronavirus", The New York Times, 7 de febrero de 2020, https://www.nytimes.com/2020/02/06/world/asia/chinese-doctorLi-Wenliang-coronavirus.html (consulta del 20 de abril de 2021). 
De manera paralela, el 3 de enero, el virólogo Zhang Yongzhen, del Centro Clínico de Salud Pública de Shanghai, recibió muestras de tejidos infectados de neumonía del Hospital Central de Wuhan. En las siguientes 40 horas, el laboratorio obtuvo la secuencia genética del virus SARs-COV-2, similar en $80 \%$ al sARs. El 5 de enero, Yongzhen informó al Ministerio de Salud de China y envió el genoma al Centro Nacional de Información Biotecnológica (NCBI) de EE.uU. Después, Yongzhen viajó a Wuhan y concluyó que la situación exigía medidas urgentes para proteger a la población. En cambio, el NCBI no había publicado aún la secuencia. ${ }^{55}$ Además, las autoridades chinas no habían compartido la muestra biológica del virus con la oms ni implementado medidas de contención. ${ }^{56}$

En este entorno, Yongzhen buscó reunirse con las autoridades en Beijing; el 11 de enero, en la pista de vuelo, el investigador acordó en una llamada telefónica con el virólogo Edward Holmes, de la Universidad de Sydney, que el código genético debía compartirse. Mientras Yongzhen volaba a Beijing, Holmes publicó la secuencia en el sitio de acceso abierto Virological.org. ${ }^{57}$ La Comisión Nacional de Salud de China había prohibido a los centros de investigación la publicación de información sobre el virus; la acción era riesgosa y con potenciales consecuencias personales. Las autoridades demandaron una explicación y revisaron el laboratorio de Yongzhen en busca de un ilícito; como lo señaló el científico: "Tal vez no pudieron entender cómo obtuvimos la secuencia”. 58,59

${ }^{55}$ Charly Campbell, "Exclusive: The Chinese Scientist Who Sequenced the First Covid-19 Genome Speaks Out About the Controversies Surrounding His Work", Time, 24 de agosto de 2020, https://time.com/58 82918/zhang-yongzhen-interview-china-coronavirus-genome (consulta del 10 de abril de 2021).

56 The Independent Panel for Pandemic Preparedness and Response, Second Report on Progress, who, 2021.

${ }^{57}$ Jon Gertner, "Unlocking the Covid Code", The New York Times, 25 de marzo de 2021, https:/ /www.nytimes.com/interactive/2021/03/25/magazine/ genome-sequencing-covid-variants.html (consulta del 28 de abril de 2021).

${ }^{58}$ Campbell, art. cit.

${ }^{59} \mathrm{El}$ autor realizó la traducción de citas textuales. 
Aunque en el documento Marco de Preparación para una Gripe Pandémica (2011) no se contempla el intercambio de secuencias genéticas, los límites entre éstas y las muestras biológicas son cada vez más difusos debido al avance en la ingeniería genética y las técnicas de genética inversa. Por lo tanto, la publicación abrió a la comunidad internacional el monopolio de la información de las autoridades chinas sobre las características del virus y el riesgo epidemiológico. ${ }^{60} \mathrm{El}$ acceso abierto de la secuencia también impulsó la I+D. Así, nueve días después de la publicación, un grupo de investigadores alemanes desarrolló el primer kit de diagnóstico para Covid-19.

La secuencia genética posibilitó los primeros proyectos de vacuna. El mismo día de la publicación, la Dra. Teresa Lambe, de la Universidad de Oxford, comenzó a trabajar en una vacuna -actualmente AstraZeneca-Oxford- ${ }^{61}$ El 13 de enero, Moderna inició el primer proyecto comercial. A su vez, grupos académicos, como el Imperial College, de Londres y la Universidad de Queensland, condujeron nueve proyectos seguidos de una iniciativa comercial de la farmacéutica Janssen, de Johnson \& Johnson. ${ }^{62}$

La detección de casos en Tailandia, Japón y EE.Uu., aunada a las crecientes evidencias científicas sobre la transmisibilidad del coronavirus, aumentaron la presión internacional sobre China. Además, la censura interna había transformado la preocupación de los ciudadanos ante la extraña neumonía en un movimiento que exigía libertad de expresión y disputaba activamente la versión oficial en redes sociales. Estos elementos perfilaban una crisis política sin precedentes desde las manifestaciones de Tiananmen. ${ }^{63}$

${ }^{60}$ Fearnley, art.cit.

${ }^{61}$ Chris Woolston, “'I've never worked harder': the race to develop a covid-19 vaccine”, Nature, 587 (2020), pp. 322-322.

62 Shrotri, Swinnen, Kampmann y Parker, art. cit.

63 Gerry Shih, "In coronavirus outbreak, China's leaders scramble to avert a Chernobyl moment", The Washington Post, 29 de enero de 2020, https://www.washingtonpost.com/world/asia_pacific/in-coronavirus- 
El gobierno de Xi Jinping reaccionó de manera contundente. El 20 de enero, la Academia Militar de Ciencias Médicas y el Instituto de Biotecnología de Beijing iniciaron la investigación de vacunas que posteriormente se asociaría con CanSino Biologics y la farmacéutica Estatal Sinopharm. Al día siguiente, tres semanas después de la detección del brote y la identificación de decenas de casos, incluido el personal médico, China reconoció la transmisión entre humanos. El 23 de enero, se implantó una cuarentena en la provincia de Hubei, acompañada de estrictas medidas de confinamiento en las zonas urbanas y la utilización de herramientas para el rastreo de contagios basadas en la geolocalización $;{ }^{64}$ entre otros efectos, estas medidas causaron escasez de suministros médicos en el mercado internacional. Finalmente, el 29 de enero, Xi Jinping, presidente de China, y Tedros Adhanom, director general de la oms, dieron una conferencia de prensa conjunta en la que se respaldaba la gestión gubernamental y se expresaba confianza a la comunidad internacional sobre la contención de la epidemia.

\section{La propagación internacional: relevancia contextual y el régimen de $I+D$}

El SARS-Cov-2 se dispersó a las ciudades globales a través de las rutas áreas, afectando inicialmente Europa y EE.UU. Este contexto movilizó a actores centrales en el ecosistema global de I+D biomédico ${ }^{65}$ y estimuló la adopción de prácticas que facilitaron la producción y la circulación de conocimiento.

outbreak-chinas-leaders-scramble-to-avert-a-chernobyl-moment/2020/01/ 29/bc4eb52a-4250-11ea-99c7-1dfd4241a2fe_story.html (consulta del 24 de abril de 2021).

64 David Cyranoski, "What China's coronavirus response can teach the rest of the world", Nature, 579 (2020), pp. 479-481.

65 Red de actores privados, públicos y sociales que intervienen en el financiamiento, la producción, la publicación y el acceso de conocimiento y en el desarrollo tecnológico. 
Las variaciones en las epistemologías cívicas delinearon los efectos políticos domésticos que promovieron la canalización de recursos para la investigación. De esta manera, la disponibilidad de conocimiento, las condiciones favorables para la I+D y la relevancia contextual que adquirió la pandemia en el Norte global detonaron los proyectos de vacuna.

El 31 de enero de 2020, la oms emitió la declaratoria de PHEIC. Ese día, la fundación Wellcome lanzó una iniciativa para compartir la investigación sobre el SARS-COV-2, que proponía medidas como el acceso abierto de las publicaciones y versiones de preprensa para agilizar la disponibilidad de los datos. Durante febrero, más de 100 instituciones académicas, centros de investigación, agencias de cooperación y fundaciones se sumaron a la propuesta, la cual fue suscrita por las editoriales nodales en la producción global de conocimiento (Elsevier, Springer Nature, The Lancet, SAGE Publishing, PLOS, entre otras).${ }^{66}$ La iniciativa catalizó la acumulación y difusión del conocimiento esencial para la factibilidad técnica de las vacunas $y,{ }^{67}$ para mayo, el motor de búsqueda de literatura biomédica Pubmed tenía 22234 artículos sobre la covid-19, en contraste con las 9291 publicaciones sobre el ébola desde 1977.68

La declaratoria de emergencia internacional canalizó los primeros financiamientos para los proyectos de vacuna. El 31 de enero, el magnate Jack Ma, fundador de Alibaba, donó 5.8 millones de dólares a los proyectos de vacuna de la Academia Militar de Ciencias Médicas. ${ }^{69}$ El 3 de febrero, con recursos

66 "Sharing research data and findings relevant to the novel coronavirus (COvID-19) outbreak", Wellcome, 31 de enero de 2020, https:/ / well come.org/coronavirus-covid-19/open-data (consulta del 19 de marzo de 2021).

67 Kai Kupferschmidt, "Preprints bring 'firehose' of outbreak data", Science, 367 (2020), pp. 963-964.

68 Principal motor de búsqueda de literatura biomédica. Véase, Pub MED, https:/ / pubmed.ncbi.nlm.nih.gov/ (consulta del 20 de abril de 2021).

69 "Jack Ma Commits \$14.4 Million for Coronavirus Vaccine Efforts", PND by Candid, 31 de enero de 2020, https://philanthropynewsdigest. 
de la Fundación Bill y Melinda Gates (100 millones de dólares) y Welcome Trust (13 millones de dólares), la Coalition for Epidemic Preparedness Innovations (CEPI) abrió una convocatoria para el financiamiento del desarrollo de la vacuna, que fue clave en la etapa inicial de proyectos como Moderna, CureVac y Novavax. ${ }^{70}$ Además, el Ru destinó 27 millones de dólares para la I+D en medicamentos y vacunas que financiaron proyectos, como el de la Universidad de Oxford. ${ }^{71}$

La UE dio inicio a la preparación para la contención de la pandemia al destinar recursos al Centro Europeo para la Prevención y Control de Enfermedades para la distribución de los kits de diagnóstico. En cambio, en EE.uu., el adelgazamiento de los Centros de Control y Prevención de Enfermedades durante la administración de Donald Trump, aunado a la percepción gubernamental sobre la misma, afectaron la respuesta institucional. ${ }^{72}$ Esa administración se rehusó a emplear el kit de diagnóstico alemán para impulsar el desarrollo de una prueba estadounidense. Tras el proceso de I+D se distribuyeron 160000 pruebas que fueron retiradas por un problema de fabricación, lo cual detuvo la distribución hasta el 28 de febrero. ${ }^{73}$ El gobierno se mostraba confiado en que

org/news/jack-ma-commits-14.4-million-for-coronavirus-vaccine-efforts (consulta del 18 de febrero de 2021).

70 "CEPI launches new call for proposals to develop vaccines against novel coronavirus, 2019-nCoV”, Coalition for Epidemic Preparedness Innovations (CEPI), 3 de febrero de 2020, https://cepi.net/news_cepi/cepilaunches-new-call-for-proposals-to-develop-vaccines-against-novel-corona virus-2019-ncov/ (consulta del 15 de diciembre de 2020).

${ }^{71}$ Gobierno del Reino Unido, Department of Health and Social Care, “£20m announced to fund vaccines for coronavirus and other infectious diseases", 3 de febrero de 2020, https://www.gov.uk/government/news/ 20m-announced-to-fund-vaccines-for-coronavirus-and-other-infectious-di seases (consulta del 24 de febrero de 2021).

${ }^{72}$ Sharmila Devi, "Us public health budget cuts in the face of covID-19", The Lancet Infectious Diseases, 20 (2020), p. 415.

73 Peter Whoriskey y Neena Satija, "How U.s. coronavirus testing stalled: Flawed tests, red tape and resistance to using the millions of tests 
la pandemia sería contenida en China y restringió la implementación de medidas preventivas. ${ }^{74}$

La crisis sanitaria en Europa, además de incentivar la canalización de recursos, promovió medidas organizativas clave para la coordinación transnacional de la investigación. La UE destinó 122 millones de dólares para el desarrollo de medicamentos y vacunas. ${ }^{75}$ La oms publicó la hoja de ruta para la $\mathrm{I}+\mathrm{D}$, la cual establecía las prioridades relativas a la investigación de vacunas y directrices para acelerar los ensayos clínicos. En colaboración con Francia, la UE y la Fundación Bill y Melinda Gates, la oms impulsó el Fondo de Respuesta Solidaria COVID-19 para financiar, entre otras medidas, el Acelerador de acceso a herramientas para la COVID-19 (ACT-Accelerator). ${ }^{76}$

Los efectos diferenciados de la epidemia en la UE, sumados a la escasez global en los suministros médicos, generaron disputas y la politización del abastecimiento. La saturación de los servicios sanitarios en Italia y España causó situaciones problemáticas como el equipamiento inadecuado del personal médico y la priorización de respiradores. Si bien Alemania y Francia habían establecido restricciones a la exportación de equipamiento médico para resguardar el suministro interno, esto fue percibido en España e Italia como una muestra de la falta de solidaridad de los socios comunitarios. ${ }^{77}$ En cambio, China envió expertos, respiradores, masca-

produced by the wHO", The Washington Post, 16 de marzo de 2020, https:/ / www.washingtonpost.com/business/2020/03/16/cdc-who-coronavirustests / (consulta del 4 de diciembre de 2020).

74 Jordyn Phelps y Karen Travers, "Trump not concerned China may be covering up full extent of coronavirus outbreak", ABC News, 7 de febrero de 2020, https://abcnews.go.com/Politics/trump-concerned-china-co vering-full-extent-coronavirus-outbreak/story?id=68824019 (consulta del 19 de noviembre de 2020).

75 European Commission (EC), “COvID-19: EU working on all fronts, $€ 232$ million for global efforts to tackle outbreak”, Bruselas, EC, 2020.

76 who, A Coordinated Global Research Map, Geneva, who, 2020.

77 “¿Qué pasara con la ue tras el Covid-19?”, La Vanguardia, 30 de marzo de 2020, https://www.lavanguardia.com/participacion/debates/20200 
rillas y medicamentos. La contención epidemiológica había liberado las capacidades domésticas de manufactura y la acción mostraba eficacia a nivel interno, a la par que contrarrestaba la narrativa adversa en el exterior. Las donaciones se extendieron a Grecia, Portugal y Hungría, entre otros, generando críticas que favorecían a los movimientos opositores a la UE. ${ }^{78}$

En el RU, la estrategia sanitaria se había orientado a que la propagación controlada del virus generara la inmunidad comunitaria. El 16 de marzo, un grupo de expertos del Colegio de Londres, la Universidad de Cambridge y el Hospital Real de Londres publicaron la preimpresión de un análisis que demostraba que la estrategia sanitaria ocasionaría más de 62000 muertes en un año. ${ }^{79}$ El estudio desató una controversia mediática en la que especialistas, personal sanitario y paneles gubernamentales cuestionaron los supuestos técnicos de la estrategia que enmarcó el establecimiento de medidas de contención.

El aumento de casos en Nueva York evidenció las deficiencias en la gestión epidemiológica. Las limitaciones en las pruebas de diagnóstico impedían el rastreo y el aislamiento de la cadena de contagios, y las disputas entre el gobierno federal y el estatal -del Partido Demócrata-, obstaculizaron la implementación de medidas de contención. ${ }^{80}$ Frente a la crisis sanitaria, el 27 de marzo, la Ley de Ayuda, Alivio y Seguridad Económica por el Coronavirus (CARES, por sus siglas en inglés), aprobada por el congreso estadounidense, destinó 2.2 billones de dólares para la gestión de los efectos eco-

330/48160119733/debate-futu ro-union-europea-crisis-coronavirus-covid19-brexit.html (consulta del 15 de diciembre de 2020).

78 Raj Verma, "China's 'mask diplomacy' to change the covid-19 narrative in Europe”, Asia Europe Journal, 18 (2020), pp. 205-209.

${ }^{79}$ Amitava Banerjee, Suliang Chen, Laura Pasea, et al., "Excess deaths in people with cardiovascular diseases during the CoviD-19 pandemic", European Journal of Preventive Cardiology, 2021, https://doi.org/10.1093/ eurjpc/zwaa155

${ }^{80}$ Whoriskey y Satija, art. cit. 
nómicos y sanitarios de la pandemia. Un mes después que la uE y dos después que China, el paquete designaba 83000 millones para $\mathrm{I}+\mathrm{D} .{ }^{81}$

En este contexto, entre febrero y marzo, farmacéuticas e instituciones académicas iniciaron 82 proyectos de vacuna. De estos, $41 \%$ se basó en o tuvo colaboración con Ee.UU., seguido de sus contrapartes europeas $(28 \%)$ y chinas $(12 \%) .{ }^{82}$ No obstante, las variaciones en la propagación de la epidemia, la gestión gubernamental y las políticas de I+D generaron diferencias en el avance de los proyectos. En China, el 23 de marzo, la Academia Militar de Ciencias Médicas y CanSino iniciaron los ensayos clínicos con sujetos humanos. ${ }^{83} \mathrm{En}$ la UE, proyectos como CureVac y BioNTech, además de preparar la etapa clínica, trabajaban en la reconversión de plantas para iniciar la producción de las vacunas antes de su autorización. ${ }^{84}$ En cambio, en EE.UU., el 30 de marzo, el Departamento de Salud acordó el cofinanciamiento con Moderna (887 millones de dólares) y Johnson \& Johnson (456 millones de dólares) para que éstos iniciaran la investigación clínica. ${ }^{85}$

${ }^{81}$ Coronavirus Aid, Relief, and Economic Security Act, Public Law No. 116-136, 134 Stat., 281 (2020).

${ }^{82}$ Estimación propia con base en los datos de Shrotri, Swinnen, Kampmann y Parker, art. cit.

83 "China begins Phase I trial of Covid-19 vaccine", Clinical Trials Arena, 23 de marzo de 2020, https://www.clinicaltrialsarena.com/news/ china-covid-19-vaccine-trial-begins/ (consulta del 12 de diciembre de 2020); Jon Cohen, "China's vaccine gambit", Science, 2020, 370 (6522), pp. 1263-1267.

${ }^{84}$ Angus Chen, “We're Racing Time': Biotech Companies Rush To Complete Coronavirus Vaccine", WBUR, 21 de febrero de 2020, https:/ / www.wbur.org/news/2020/02/21/were-racing-time-biotechnology-com panies-rush-to-complete-coronavirus-vaccine (consulta del 12 de diciembre de 2020).

${ }^{85}$ Julie Steenhuysen, "J\&J, Moderna sign deals with U.S. to produce huge quantity of possible coronavirus vaccines", Reuters, 30 de marzo de 2020, https://www.reuters.com/article/us-health-coronavirus-johnson-jo hnson-idUSKBN21H1OY (consulta del 9 de diciembre 2020). 


\section{Estados Unidos y China: LA MANUFACTURA DE IMAGINARIOS SOCIOTÉGNICOS}

Para abril de 2020, EE.UU. se convertía en el epicentro global de la pandemia y sus efectos erosionaban los pilares materiales y simbólicos del proyecto político de Trump: la reconstrucción de la grandeza estadounidense y el prolongado ciclo de expansión económica. Mientras el Partido Demócrata comenzaba a unificarse en torno a Joe Biden, la pandemia sustanciaba el discurso opositor. En este entorno, el presidente Trump y el titular de la Secretaría de Estado, Mike Pompeo, acusaron a China y a la oms de encubrir el brote de COVID-19, e incluso atribuyeron, sin evidencia, su origen al Instituto de Virología de Wuhan. ${ }^{86}$ En China, la narrativa oficial delineó, sin aportar pruebas, un origen del coronavirus en el ejército estadounidense. ${ }^{87}$ Para mayo, Trump evocaba el patriotismo estadounidense, equiparando la pandemia a un ataque militar: "Éste es realmente el peor ataque que hemos tenido [...] peor que Pearl Harbor [...] que el World Trade Center [...] Podría haberse detenido en China". 88

A principios de mayo, la administración de Trump planteó la reapertura económica pero, a diferencia de la UE y China, los contagios seguían en aumento. Frente a las críticas de opositores y expertos, el gobierno minimizó los riesgos sanitarios argumentando que el virus desaparecería en cualquier mo-

86 "The Wuhan Lab Theory", The Wall Street Journal, 6 de mayo de 2020, https://www.wsj.com/articles/the-wuhan-lab-theory-11588806940 (consulta del 22 de noviembre de 2020).

${ }^{87}$ Vanessa Molter y Renee DiResta, "Pandemics \& propaganda: how Chinese state media creates and propagates CCP coronavirus narratives", Harvard Kennedy School Misinformation Review, 2020, 1(3).

${ }^{88}$ The White House, "Remarks by President Trump at Signing of a Proclamation in Honor of National Nurses Day", 6 de mayo de 2020, https://trumpwhitehouse.archives.gov/briefings-statements/remarkspresident-trump-signing-proclamation-honor-national-nurses-day/ (consulta del 24 de noviembre de 2020). 
mento. ${ }^{89}$ En esta controversia, el discurso de Trump recurrió el tema de las vacunas para plantear una alternativa a las recomendaciones de mantener el confinamiento, por lo que su desarrollo se imbricó con la administración gubernamental de las expectativas de la ciudadanía sobre el tema. Por ejemplo, Trump declaraba: "Yo creo que nos está yendo muy bien con las vacunas [...] va a pasar y volaremos a la normalidad $[\ldots] " .{ }^{90}$

El 15 de mayo, Trump lanzó la Operation Warp Speed (ows) para asegurar las vacunas para los estadounidenses antes de enero de 2021. Coordinada por el Departamento de Defensa y el Departamento de Salud, con un presupuesto que alcanzaría 18000 millones de dólares, la ows aceleraría el desarrollo de proyectos comerciales, aseguraría la inmunización de los 300 millones de habitantes y planearía la logística para una rápida distribución. También coordinaría las dependencias federales para agilizar los ensayos clínicos y la autorización. ${ }^{91}$ Publicitada como "un esfuerzo científico, industrial y logístico masivo, diferente a todo lo que nuestro país ha visto desde el Proyecto Manhattan", ${ }^{92}$ la ows reelaboró el imaginario de la grandeza estadounidense en un proyecto que utilizaría sus amplias capacidades financie-

${ }^{89}$ The White House, "Remarks by President Trump and Vice President Pence in Roundtable with Industry Executives on the Plan for Opening Up America Again", 29 de abril de 2020, https://trumpwhitehouse. archives.gov/briefings-statements/remarks-president-trump-vice-presi dent-pence-roundtable-industry-executives-plan-opening-america/ (consulta del 23 de noviembre de 2020).

90 "Transcript: ABC News anchor David Muir interviews President Trump in Arizona", ABC News, 6 de abril de 2020, https://abcnews.go. $\mathrm{com} /$ Politics/transcript-abc-news-anchor-david-muir-interviews-presi $\mathrm{dent} /$ story?id=70523003 (consulta del 22 de noviembre de 2020).

${ }^{91}$ Jerome H. Kim et al., "Operation Warp Speed: implications for global vaccine security", The Lancet Global Health, 2021, núm. 9, pp. 1-5.

92 The White House, "Remarks by President Trump on Vaccine Development", 15 de mayo de 2020, https://trumpwhitehouse.archives.gov/ briefings-statements/remarks-president-trump-vaccine-develop ment/ (consulta del 17 de diciembre de 2020). 
ras, militares y técnicas para materializar y asegurar primero las vacunas.

Al mismo tiempo, en China, en la narrativa oficial, el pueblo lideraba el frente global contra la epidemia con "hazañas heroicas de los miembros y cuadros del partido" y los "guerreros blancos", en que las vacunas lograrían la victoria estratégica. ${ }^{93} \mathrm{El}$ avance en las vacunas se presentaba como evidencia del desarrollo nacional y un motivo de orgullo para la población que había padecido la severa contención sanitaria. ${ }^{94}$ La efectiva contención de la epidemia había estrechado la urgencia de la inmunización doméstica. En cambio, la donación de suministros médicos había mostrado el alcance de la diplomacia sanitaria y había fortalecido la relación con diversos gobiernos, en particular, frente al repliegue estadounidense de la cooperación sanitaria en África, Asia y Latinoamérica. ${ }^{95}$

En este contexto, el desarrollo de las vacunas se orientó al abastecimiento externo; en la Asamblea Mundial de la Salud, Xi Jinping señaló: "El desarrollo y despliegue de la vacuna [...] en China [...] se convertirá en un bien público mundial. Ésta será la contribución [para] los países en desarrollo". ${ }^{96}$ Sin embargo, las patentes de estas vacunas no habían sido liberadas y los mecanismos e instituciones multilaterales tampoco administraban el abastecimiento. Las vacunas serían

93 "Six-episode large-scale documentary: Fighting with the Epidemic", Xinhua News Agency, 31 de agosto de 2020, http://www.xhby.net/tuijian/202008/t20200831_6785354.shtml (consulta del 11 de marzo de 2021).

${ }^{94}$ Flynn Murphy, "Inside China's Response to Covid", Nature, 588 (2020), pp. 49-51.

${ }^{95}$ Gobierno de la República Popular de China, Ministry of Foreign Affairs of the People's Republic of China, "MFA: China has Announced Assistance to 82 Countries, wHO and African Union to Fight Covid-19", 20 de marzo de 2020, https://www.fmprc.gov.cn/mfa_eng/topics_665678/ kjgzbdfyyq/t1759145.shtml (consulta del 12 de diciembre de 2020).

96 Xi Jinping, "Fighting covid-19 Through Solidarity and Cooperation Building a Global Community of Health for All", Virtual Event of Opening of the 73rd World Health Assembly, 18 de mayo de 2020. 
accesibles, pero China controlaría y mediaría la I+D, la producción, la negociación y el esquema de financiamiento. Con lo anterior, el imaginario del bien público global se traducía en una disposición de carácter paternalista que se constituía como una alternativa al vacío estadounidense y legitimaba el establecimiento de relaciones de dependencia.

\section{La competencia internacional}

Las agendas políticas y diplomáticas generaron una competencia internacional por las vacunas. Previamente, los actores habían promovido y financiado la investigación sin establecer un compromiso directo con los proyectos. Con la competencia internacional, el foco de interés se desplazó de la I+D al control de la investigación, la producción y el acceso, lo cual obstaculizó las alternativas para el desarrollo internacional de las vacunas.

El gobierno estadounidense buscó el control y el suministro prioritario de los proyectos de vacuna europeos más avanzados; por ejemplo, estableció un acuerdo con AstraZeneca para la compra de 300 millones de dosis, aunque, el convenio con la Universidad de Oxford, en donde se desarrolló la patente, limitaba el acaparamiento. En contraste, se ofrecieron 1000 millones de dólares a la farmacéutica alemana CureVac por la exclusividad y el traslado del proyecto a EE.UU., lo cual superaba el presupuesto que hasta ese momento la UE había destinado para $\mathrm{I}+\mathrm{D}$. Los ministros de relaciones exteriores y economía respondieron con declaraciones como "Alemania no está a la venta", ${ }^{97}$ e incluso la oficina de Ángela Merkel medió con la compañía para evitar la operación. Por otro lado, el acuerdo con Sanofi Pasteur, con la

97 "Coronavirus: anger in Germany at report Trump seeking exclusive vaccine deal", The Guardian, 16 de marzo de 2020, https://www.theguard ian.com/world/2020/mar/16/not-for-sale-anger-in-germany-at-reporttrump-seeking-exclusive-coronavirus-vaccine-deal (consulta del 19 de noviembre de 2020). 
mayor capacidad de manufactura de vacunas en la UE, pactaba el abastecimiento prioritario con EE.UU. ${ }^{98}$ La controversia en Francia llevó a la intervención gubernamental; por ejemplo, el primer ministro, Édouard Philippe, publicó en Twitter: "Acabo de recordarle a Serge Weinberg, quien preside Sanofi, que esta gran empresa es profundamente francesa. Me dio todas las garantías [...] respecto a la distribución en Francia [...]".99

La estrategia de la uE para las vacunas de Covid-19, delineada por la politización de los suministros médicos, la diplomacia sanitaria de China y las disputas con EE.uU., resultó en el incremento al financiamiento para $\mathrm{I}+\mathrm{D}$, rubro al que se destinaron 3300 millones de dólares para el establecimiento de ACA, y se flexibilizó la conducción de ensayos y la autorización. Si bien la estrategia buscaba asegurar el suministro, a diferencia de EE.uU. y China, la negociación incluía a los 27 integrantes de la comunidad bajo el compromiso de colaboración y financiamiento para la provisión global a través de la OMs. ${ }^{100}$ Los principales receptores de recursos destinados a investigación fueron CureVac y BioNTech, y el primer ACA se realizó con Sanofi Pasteur por 300 millones de vacunas.

La intermediación de China en el acceso a las vacunas fue un factor en la politización y competencia internacional. La primera asociación internacional de CanSino fue con Precision NanoSystems, la cual contó con fondos del gobierno canadiense para la adopción del equipamiento. No obstante, la reticencia de China a transferir la tecnología al socio cercano de EE.UU. y las tensiones con Canadá en torno al

98 "French pharma giant Sanofi to give us preference on future COVID-19 vaccine", France 24, 13 de mayo de 2020, https://www.france24. com/en/20200513-french-pharma-giant-sanofi-to-give-us-preference-onfuture-covid-19-vaccine (consulta del 16 de enero de 2021).

${ }^{99}$ Edouard Philipe, Twitter, @EPhilippe_LH, 14 de mayo de 2020, https://twitter.com/EPhilippe_LH/status/1260886560704258048?s=20 (consulta del 16 de enero de 2021).

${ }^{100}$ European Commission, EU Strategy for COVID-19 vaccines, Bruselas, 2020. 
comercio tecnológico llevaron a la cancelación del proyecto, ${ }^{101}$ revés tras el cual Canadá implementó una agresiva estrategia de ACA con las farmacéuticas transnacionales. Por otra parte, en la región del Mar de China, donde se han presentado diversas disputas territoriales y comerciales, los efectos fueron heterogéneos. ${ }^{102} \mathrm{El}$ involucramiento de China en la negociación de acuerdos bilaterales causó controversia por sus implicaciones políticas y financieras en Filipinas y Bangladesh, y en Vietnam y Tailandia fue un incentivo para el desarrollo de proyectos domésticos. ${ }^{103}$

Rusia e India, con distintos recursos y estrategias, incursionaron en la competencia global. A finales de mayo, Rusia hizo público el proyecto del Centro Gamaleya financiado por el Fondo Soberano de Inversión de Rusia. El prestigioso laboratorio estatal, clave en el avance biomédico de la Unión Soviética, acumulaba experiencia relevante en el desarrollo de vacunas. ${ }^{104}$ India se enfocó en asegurar la soberanía en el abastecimiento; la extensa capacidad de manufactura del Serum Institute fue un elemento en la negociación con AstraZeneca y se promovieron proyectos de las farmacéuticas domésticas orientados al mercado interno. ${ }^{105}$

Frente a la competencia internacional, el 26 de junio, el ACT-Accelerator de la oms propuso la formación de covax,

101 Sam Cooper, "China blamed for Canada's multimillion-dollar coronavirus vaccine deal collapse”, Global News, 28 de agosto de 2020, https:/ / globalnews.ca/news / 7302194/canada-coronavirus-vaccine-dealchina/ (consulta del 10 de diciembre de 2020).

102 Khairulanwar Zaini, "China's Vaccine Diplomacy in Southeast Asia-A Mixed Record”, ISEAS Perspective 2021, núm. 86, 2021.

103 "China's Covid-19 vaccine diplomacy steals a march on US", $\mathrm{Fi}$ nancial Times, 12 de noviembre de 2020, https://www.ft.com/content/ ce9a4c98-49b5-4c24-9ff2-ed1c6a3f3412 (consulta del 12 de diciembre de 2020).

104 Jadwiga Rogoża y Iwona Wiśniewska, "Russia in the global "vaccine race"”, osw Commentary, 359 (2020), pp. 1-6.

105 Sahil Deo, Shardul Manurkar, Sanjana Krishnan y Christian Franz, "Covid-19 Vaccine: Development, Access and Distribution in the Indian Context”, orF Issue Brief, 378 (2020), p.16. 
un fondo multilateral con financiamiento gubernamental y privado para el desarrollo, la producción y la distribución equitativa de vacunas entre países durante 2021. Aunque la iniciativa era una solución parcial a la disputa, esta organizaría a financiadores, desarrolladores, productores y consumidores, lo cual, entre otros beneficios, diversificaría las vacunas disponibles, ampliaría el acceso y reduciría tanto los costos globales de la inmunización como los incentivos para el acaparamiento y el uso político (véase el cuadro 1). ${ }^{106}$ La iniciativa sumó el apoyo de 150 países, entre ellos, Alemania, Sudáfrica, Corea y México. Sin embargo, la ausencia de EE.uU., China y Rusia, competidores centrales, impidió que covax se constituyera como un esquema organizativo efectivo. ${ }^{107}$

\section{CUAdro 1}

covax y sus beneficios potenciales

\begin{tabular}{|c|c|c|}
\hline Pilares & Beneficios & Efectos en el desarrollo \\
\hline $\begin{array}{l}\text { Financiamiento } \\
\text { basado en un fondo } \\
\text { multilateral de } 2000 \\
\text { millones de dólares }\end{array}$ & $\begin{array}{l}\text { - Colectivización del financiamiento } \\
\text { - Reducción en los costos globales } \\
\text { - Acceso a países de ingresos bajos }\end{array}$ & 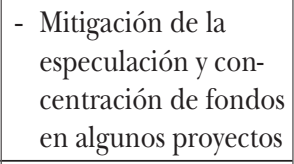 \\
\hline Portafolio de I+D & $\begin{array}{l}\text { - Diversificación de la cartera global de } \\
\text { vacunas que serían desarrolladas } \\
\text { - Reducción en el riesgo de inversión en } \\
\text { proyectos individuales } \\
\text { - Menores incentivos para la exclusividad } \\
\text { de patentes }\end{array}$ & \begin{tabular}{|l} 
- \\
Desarrollo de \\
distintas tecnologías \\
- Diversificación en las \\
características de los \\
proyectos disponibles \\
- Coordinación \\
transnacional en los \\
ensayos
\end{tabular} \\
\hline
\end{tabular}

${ }^{106}$ Ezekiel J. Emanuel, Govind Persad, Adam Kern et al., "An ethical framework for global vaccine allocation”, Science, 369 (2020), pp. 13091312; World Health Organization (wHO), "What is the Access to Covid-19 Tools (АСт) Accelerator, how is it structured and how does it work?", Suiza, wHo, 2021.

${ }^{107}$ Oxfam International, art. cit. 


\section{Cuadro 1 (conclusión) covax y sus beneficios potenciales}

\begin{tabular}{|c|c|c|}
\hline $\begin{array}{l}\text { Producción de dosis } \\
\text { para } 2000 \text { millones } \\
\text { de personas }\end{array}$ & $\begin{array}{l}\text { - Aumento en la costo-efectividad de las } \\
\text { inversiones en ampliación } \\
\text { - Menores incentivos para el } \\
\text { abastecimiento prioritario y la } \\
\text { securitización industrial }\end{array}$ & $\begin{array}{l}\text { - Optimización de } \\
\text { capacidades } \\
\text { instaladas } \\
\text { - Incentivos para la } \\
\text { transferencia de } \\
\text { tecnología }\end{array}$ \\
\hline $\begin{array}{l}\text { Distribución equita- } \\
\text { tiva entre países }\end{array}$ & $\begin{array}{l}\text { - Abastecimiento del } 20 \% \text { de la } \\
\text { población de cada país } \\
\text { - Inmunización del personal sanitario } \\
\text { y grupos con mayor riesgo a nivel } \\
\text { nacional } \\
\text { - Disminución de la mortalidad en cada } \\
\text { país y a nivel global }\end{array}$ & $\begin{array}{l}\text { - Coordinación y } \\
\text { mayor eficiencia en } \\
\text { la cadena } \\
\text { abastecimiento }\end{array}$ \\
\hline
\end{tabular}

Fuente: elaboración propia con base en Ezekiel J. Emanuel, Govind Persad, Adam Kern et al., "An ethical framework for global vaccine allocation”, Science, 369 (2020), pp. 1309-1312 y World Health Organization (wHo), "What is the Access to covid-19 Tools (ACT) Accelerator, how is it structured and how does it work?", Suiza, wHo, 2021.

Autorización: epistemologías cívicas y la aceptabilidad de la relación riesgo-beneficio

El 11 de agosto de 2020, Vladimir Putin, presidente de Rusia, anunció la autorización de la primera vacuna disponible a nivel mundial, la Sputnik V. Los datos clínicos de las fases I y II mostraban que la vacuna producía una respuesta inmunológica y efectos secundarios menores. En estas fases, como es usual, el número de participantes fue reducido y en su mayoría, personal militar y de origen caucásico. ${ }^{108}$ La fase III era necesaria para evaluar los efectos en distintos grupos

${ }^{108}$ Denis Y. Logunov, Inna V Dolzhikova, Olga V Zubkova et al., "Safety and immunogenicity of an rAd26 and rAd5 vector-based heterologous prime-boost covid-19 vaccine in two formulations: two open, non-randomised phase 1/2 studies from Russia", The Lancet, vol. 396 (2020), pp. 887-897. 
(p. ej., en adultos mayores, mujeres y otras etnicidades), así como la efectividad de la respuesta inmune contra covid-19 (véase el cuadro 2). Pese a que los resultados eran prometedores, los datos clínicos aún no sustentaban la seguridad ni la efectividad. ${ }^{109}$ Llamada como el primer satélite ruso, en 1957, que constituyó un hito en la carrera espacial, la vacuna Sputnik se entiende como una representación del proyecto político de Putin: la restauración de Rusia como potencia global. ${ }^{110}$ La autorización no tenía como objetivo garantizar la confiabilidad médica, sino que era un acto en el que se promulgaba el significado de la vacuna, lo cual enmarcó las posteriores controversias sobre su seguridad.

Una semana después, en China, se autorizó CoronaVac con los ensayos clínicos de fase II. A la par, Trump presionaba a la Administración de Drogas y Alimentos (FDA) para la autorización del proyecto de Oxford-AstraZeneca antes de las elecciones; en Twitter publicó: "El estado profundo, o quien sea, en la FDA está haciendo muy difícil que las compañías farmacéuticas logren que la gente pruebe las vacunas [...]". ${ }^{111}$ La activa oposición de la comunidad científica estadounidense llevó a que un grupo de altos funcionarios de la FDA refrendaran públicamente la autonomía de la institución y se comprometieran a mantener los requerimientos clínicos. ${ }^{112}$ Aun así, las expectativas sobre una inminente autorización eran altas y, durante agosto, diversos países, incluidos México, Corea del Sur, Brasil y Australia, firmaron acuerdos con AstraZeneca por un suministro de dosis para inmunizar a 2940 millones de personas.

109 Naor Bar-Zeev y Tom Inglesby, “COvid-19 vaccines: early success and remaining challenges", The Lancet, vol. 396 (2020), pp. 868-869.

${ }^{110}$ Valeria Vargina, "Sputnik V Vaccine as a Soft-Power Instrument of Russia”, Journal of Governance and Politics, 2020, 2(7), en preprensa.

111 Donald Trump, Twitter, 22 de agosto de 2020, @realDonaldTrump, https:/ / twitter.com/realDonaldTrump/status / 1297138862108663808 (consulta del 17 de noviembre de 2020).

112 "Trumping science", Nature Biotechnology, 38 (2020), pp. 1105, https://doi.org/10.1038/s41587-020-0713-y 


\section{Cuadro 2 \\ Ensayos clínicos}

\begin{tabular}{|l|l|l|}
\hline \multicolumn{1}{|c|}{ Fases } & \multicolumn{1}{|c|}{ Características } & \multicolumn{1}{|c|}{ Objetivos } \\
\hline I & $\begin{array}{l}\text { Se analizan distintas dosis en grupos } \\
\text { de } 20 \text { a } 100 \text { voluntarios sanos. }\end{array}$ & $\begin{array}{l}\text { Evaluar la respuesta inmunitaria, } \\
\text { la toxicidad y potenciales efectos } \\
\text { secundarios. }\end{array}$ \\
\hline II & $\begin{array}{l}\text { Se prueban diversas dosis en cientos } \\
\text { de voluntarios con diferencias } \\
\text { demográficas y en el estado de salud. }\end{array}$ & $\begin{array}{l}\text { Evaluar riesgos y efectos en el corto } \\
\text { plazo y la relación dosis/ respuesta } \\
\text { inmune. }\end{array}$ \\
\hline III & $\begin{array}{l}\text { Miles de voluntarios con diferencias } \\
\text { demográficas reciben la vacuna o un } \\
\text { placebo. }\end{array}$ & $\begin{array}{l}\text { Determinar la efectividad para } \\
\text { disminuir la incidencia de la } \\
\text { enfermedad, los principales efectos } \\
\text { secundarios y la seguridad para } \\
\text { distintos grupos. }\end{array}$ \\
\hline $\begin{array}{l}\text { Autorización } \\
\text { de uso de } \\
\text { emergencia }\end{array}$ & $\begin{array}{l}\text { Se realizan adaptaciones a los } \\
\text { protocolos y duración de los ensayos. }\end{array}$ & $\begin{array}{l}\text { Poner a disposición fármacos o } \\
\text { usos no aprobados de éstos durante } \\
\text { una emergencia sanitaria. }\end{array}$ \\
\hline
\end{tabular}

Fuente: elaboración propia con base en Adriana Petryna, When experiments travel: clinical trials and the global search for human subjects, Princeton, University Press, 2009; Peter Doshi, "Covid-19 vaccine trial protocols released”, BMJ, vol. 371 (2020), m4058.

El 8 de septiembre, con el inicio de la fase III, AstraZeneca y la FDA se reunieron para discutir el proceso de autorización. ${ }^{113}$ Unas horas después, los medios informaron que el proyecto había detenido los ensayos clínicos el 6 de septiembre para indagar un padecimiento neurológico en una participante. Después, se reveló que existía un primer antecedente: una voluntaria había desarrollado una mielitis transversal y un comité independiente determinó que el padecimiento no

113 Comunicado de la reunión: "Biopharma leaders unite to stand with science", AstraZeneca (comunicado de prensa), 8 de septiembre 2020, https://www.astrazeneca.com/content/astraz/media-centre/pressreleases/2020/biopharma-leaders-unite-to-stand-with-science.html (consulta del 15 de diciembre de 2020). 
tenía relación con el fármaco. ${ }^{114}$ En el segundo caso, AstraZeneca comunicó que la investigación había demostrado que no existía una relación con la vacuna, pero se rehusó a especificar la afección. Sin embargo, el diario The New York Times publicó que los detalles habían sido compartidos de manera confidencial con los accionistas y fuentes cercanas al caso confirmaban que también se trataba de una mielitis transversal. ${ }^{115}$

La presión de la Casa Blanca a la FDA, la falta de transparencia en los ensayos y la pérdida de confianza en la farmacéutica definieron la manera en que los críticos evaluarían los riesgos del proyecto. Dos casos de mielitis transversal no tenían significancia estadística para la muestra de los ensayos, no obstante, una causa del padecimiento es la respuesta inmune a infecciones bacterianas y virales, y la vacuna se basaba en un vector de adenovirus de chimpancé, una plataforma innovadora para potenciar la respuesta inmune, pero con escasos antecedentes. ${ }^{116}$ Diversos expertos pidieron cautela en torno a una vacuna que se aplicaría al $20 \%$ de la población global y la polémica llevó a la suspensión de los ensayos clínicos. ${ }^{117}$

En las siguientes semanas, la comunidad científica estadounidense lanzó una campaña pública para demandar trans-

114 Rebecca Robins, Sharon LaFraniere, Noah Weiland, David D. Kirkpatrick y Benjamin Mueller, "Blunders Eroded u.s. Confidence in Early Vaccine Front-Runner", The New York Times, 8 de diciembre de 2020, https://www.nytimes.com/2020/12/08/business/covid-vaccine-oxfordastrazeneca.html (consulta del 18 de diciembre de 2020).

115 Katherine J. Wu, "Safety Review Underway of AstraZeneca's Vaccine Trial", The New York Times, 10 de septiembre de 2020, https://www. nytimes.com/2020/09/10/health/covid-astrazeneca-vaccine-trans.html (consulta del 7 de febrero de 2021).

${ }^{116}$ Smriti Mallapaty y Heidi Ledford, "COvid-vaccine results are on the way-and scientists' concerns are growing”, Nature, 586 (2020), pp. 16-17.

${ }^{117}$ Nicky Phillips et al., "A leading coronavirus vaccine trial is on hold: scientists react", Nature, 9 de septiembre de 2020, https://www.nature. com/articles/d41586-020-02594-w (consulta del 25 de enero de 2021); Mallapaty y Ledford, art. cit. 
parencia en los ensayos y el proceso de autorización de las vacunas. ${ }^{118}$ En respuesta, Moderna, Pfizer-BioNTech, Johnson \& Johnson y AstraZeneca publicaron los protocolos clínicos, lo cual generó una controversia sobre su efectividad: aun cuando el objetivo era reducir los casos severos y prevenir la transmisión, la investigación clínica no demostraba estos beneficios.

En la fase III de los ensayos participarían entre 30 y 44000 personas adultas que recibirían de manera aleatoria la vacuna o un placebo. La efectividad se estimaría cuando entre 150 y 160 participantes desarrollaran casos de Covid-19 definidos por una prueba positiva y la presencia de síntomas pero, dado que en la mayoría de los casos los síntomas son leves, como la fiebre o la tos, la efectividad no se valoraría respecto a los beneficios para prevenir casos severos, hospitalizaciones o fallecimientos. ${ }^{119}$ Tampoco se evaluaría la reducción de la transmisión, debido a que no se medirían aspectos como la carga viral durante el periodo de infección. La duración de los ensayos evitaría que se determinara el periodo de protección o la efectividad frente a mutaciones. ${ }^{120}$ Además, los protocolos carecían de medidas para asegurar la representatividad de grupos con alta mortalidad por el coronavirus o con mayor vulnerabilidad a los efectos secundarios, como adultos mayores con comorbilidades, afroamericanos y personas inmunocomprometidas. ${ }^{121}$

Las vacunas podrían ser seguras y efectivas para reducir la mortalidad y la transmisión, pero la investigación clínica

118 Raymond M. Johnson, Peter Doshi y David Healy, "Covid-19: Should doctors recommend treatments and vaccines when full data are not publicly available?”, $B M J, 370$ (2020), m3260.

119 Peter Doshi, “COvID-19 vaccine trial protocols released”, BMJ, 371 (2020), m4058.

120 Marc Lipsitch y Natalie Dean, "Understanding CoviD-19 vaccine efficacy”, Science, 370 (2020), 763-765.

121 Loc. cit.; Rueben C. Warren, Lachlan Forrow, David Augustin Hodge, Sr. y Robert D. Truog, "Trustworthiness before Trust - Covid-19 vaccine trials and the Black community", New England Journal of Medicine, $383(2021)$, e121. 
no lo demostraría, lo que podría afectar las estrategias de inmunización. Por ejemplo, los adultos mayores con comorbilidades eran un grupo prioritario y la incertidumbre en los datos clínicos de este grupo podría resultar en efectos secundarios que sobrepasaran los beneficios de la inmunización y, a su vez, mermar la confianza de otros grupos con una menor susceptibilidad. ${ }^{122}$ Por otro lado, la autorización era la declaratoria de los proyectos "ganadores", y si estos tenían una efectividad limitada, el cierre de la carrera afectaría el desarrollo de otros proyectos con mayores beneficios potenciales debido a la reducción en el financiamiento, el abandono de los ensayos por parte de los voluntarios o las menores facilidades de regulación.

Las farmacéuticas reconocían la importancia de una evaluación más detallada. En una entrevista con la BMJ, el director médico de Moderna, Tal Zaks, señaló: “¿Me gustaría saber que previene la mortalidad? Claro, porque creo que sí. Simplemente no creo que sea factible dentro del plazo [...]". ${ }^{123}$ La baja frecuencia de los casos severos y la complejidad de monitorear la carga viral de los voluntarios en distintos sitios eran factores que hacían necesario un incremento en el tamaño, la duración y el costo de los estudios. Al abordar la evaluación de la transmisión, Zaks argumentó: "Creo que el dinero público y las habilidades y capacidades operativas que tenemos deben gastarse correctamente [...] como está tratando la Operation Warp Speed [...]". ${ }^{124}$ De esta manera, la interpretación de la FDA y las farmacéuticas sobre las prioridades y restricciones contextuales delineó el diseño de los ensayos clínicos y los beneficios relativos aceptables.

En la recta final, el 9 de noviembre, Pfizer-BioNTech anunció una efectividad de $95 \%$. En el ensayo se identificaron

122 Roy L. Soiza, Chiara Scicluna y Emma C. Thomson, "Efficacy and safety of Covid-19 vaccines in older people", Age and Ageing, 50 (2021), 279-283.

123 Peter Doshi, "Will Covid-19 vaccines save lives? Current trials aren't designed to tell us”, BMJ, 371 (2020), m4037.

${ }^{124}$ Loc. cit. 
170 casos de infecciones (162 con el placebo) y 10 casos severos (9 con el placebo). Le siguieron los anuncios de Moderna (94.5\%), Sputnik V (95\%) y, el 22 de noviembre, el de AstraZeneca, con una efectividad de $70 \%$. Al día siguiente, esta farmacéutica rectificó a $90 \%$, debido a que la efectividad había sido mayor en un grupo de 3000 personas que recibieron por equivocación la mitad de la primera dosis. El error de la compañía y la representatividad de los resultados causó una nueva polémica que retrasó la autorización de la vacuna. ${ }^{125}$

\section{LA CONFIGURACIÓN DE LAS VACUNAS}

Resultado de la trayectoria de desarrollo, el arreglo sociotécnico de las vacunas enmarca la distribución global (véase el cuadro 3). Las características sociales de las vacunas de Pfizer/BioNTech, Moderna y Johnson \& Johnson (p. ej., naturaleza del desarrollador y orientación) han generado una estratificación de su distribución/acceso. En la primera línea se encuentra el abastecimiento de los financiadores de la I+D, como EE.UU. y Alemania; después, el cumplimiento de los Aca establecidos con gobiernos, como Canadá y Japón. Con todo, aquellos con mayor capacidad económica financiaron el desarrollo de proyectos y realizaron múltiples ACA con estas farmacéuticas y otras vacunas comerciales, como Novavax, Sanofi y CureVac, debido a los riesgos de fracaso de los proyectos individuales; así, desde agosto de 2020, el RU había asegurado más de cinco vacunas por cada habitante. ${ }^{126}$

125 Joseph Walker y Jenny Strasburg, "AstraZeneca Defends Dosing Error in Covid-19 Vaccine Trial", 25 de diciembre de 2020, https:/ /www. wsj.com/articles/astrazeneca-defends-dosing-error-in-covid-19-vaccinetrial-11606358805 (consulta del 8 de febrero de 2021).

${ }^{126}$ Ewen Callaway, "The unequal scramble for coronavirus vaccinesby the numbers", Nature, 584 (2020), pp. 506-507; Oxfam International, art. cit. 


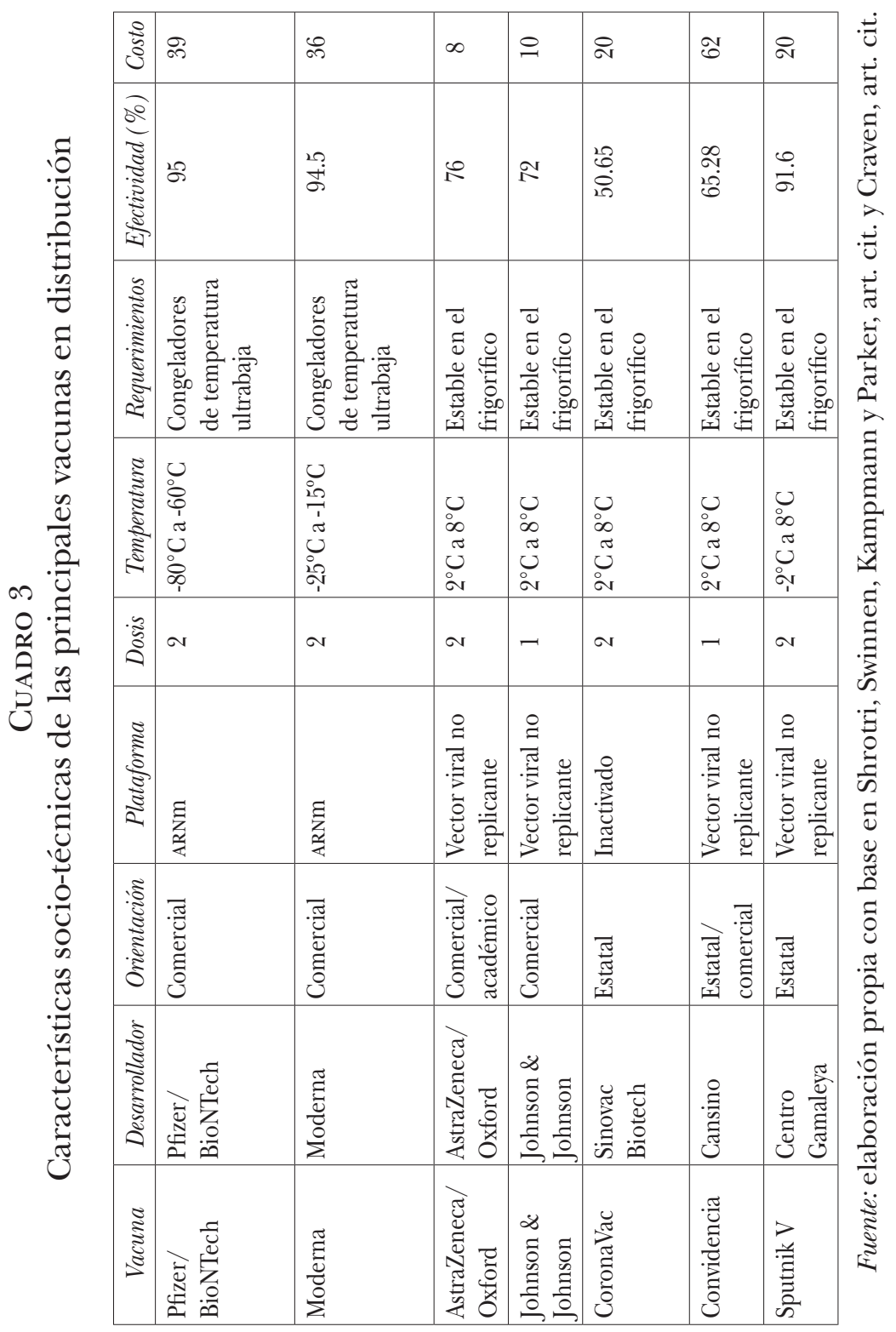


Como resultado, la producción de las vacunas comerciales durante 2021 se ha encontrado comprometida en gran medida con el Norte global. El superávit en posesión de los gobiernos puede canalizarse a través de covax o de acuerdos bilaterales, como fue el caso del préstamo que realizó EE.UU. de la reserva de AstraZeneca a México y Canadá. Esto otorga la posibilidad de hacer un uso diplomático de los excedentes, pero la falta de información sobre el periodo de protección de las vacunas y el posible reforzamiento frente a las nuevas variantes de coronavirus generan incertidumbre sobre su liberación.

Las características técnicas de las vacunas comerciales influyen, asimismo, la traducción de beneficios en distintos ambientes y grupos sociales. En el caso de Johnson \& Johnson, aun con una menor efectividad, su aplicación de una dosis, su tolerancia térmica y su costo facilitan la potencial distribución en el Sur global. La plataforma de ARN mensajero está relacionada con la mayor efectividad de los biológicos de Moderna y Pfizer/BioNTech, pero también con el costo y la cadena de frío que se requiere desde su manufactura hasta su aplicación; como consecuencia, la producción se realiza en instalaciones altamente especializadas en EE.UU. y la UE, lo cual limita una posible transferencia de la manufactura a otras geografías. ${ }^{127}$ La cadena de frío a lo largo del transporte, el almacenamiento y la aplicación tiene implicaciones en la logística y el costo de las estrategias de inmunización. Además, la infraestructura de transporte, los congeladores de temperatura ultrabaja e incluso la red eléctrica no se encuentran disponibles en diversas geografías del Sur global ni en zonas rurales. ${ }^{128}$

127 Daan J.A. Crommelina, Thomas J. Anchordoquy, David B. Volkin, Wim Jiskoot y Enrico Mastrobattista, "Addressing the cold reality of mRNA vaccine stability”, Journal of Pharmaceutical Sciences, 2021, 110 (3), pp. 997-1001.

128 World Health Organization (WHO), COVID-19 vaccination: supply and logistics guidance: interim guidance, wHO, 2021; Shahriar Tanvir Alam, Sayem Ahmed, Syed Mithun Ali, Sudipa Sarker, Golam Kabir y Asif 
La plataforma empleada en Convidencia, CoronaVac y Sputnik V ha resultado en características técnicas que facilitan una distribución más amplia en el Sur global, así como una potencial transferencia de la tecnología y la manufactura. No obstante, su acceso es negociado en acuerdos bilaterales entre gobiernos que dan preferencia a una lógica política sobre objetivos económicos o sanitarios. El entorno de escasez y el control en el suministro son favorables para la capitalización de dividendos políticos y pueden constituir una limitante a la transferencia tecnológica. Asimismo, la menor efectividad de Convidencia y CoronaVac puede traducirse en una pandemia más prolongada y retrasar la recuperación sanitaria y económica de estos países, en comparación con el Norte global. ${ }^{129}$ Además, el incumplimiento en los estándares internacionales de manufactura ha retrasado la inclusión de Sputnik V en el listado de vacunas autorizadas para uso emergente de la oms, ${ }^{130}$ un aspecto clave en la reapertura de fronteras.

La vacuna de AstraZeneca/Oxford, basada en investigación académica, ha generado una alta relación costo-efectividad y menores requerimientos técnicos; además, por su orientación, ha convenido el abastecimiento de covax, lo cual favorece la transferencia y el acceso en el Sur global. Por ejemplo, la producción de esta vacuna por el Serum Institute de India ha sido clave para la distribución internacional, incluidos países de ingresos bajos como Kenia y Nigeria. Sin embargo, las controversias de seguridad han incidido en la confianza del público, componente esencial en el uso de fármacos. ${ }^{131}$

ul-Islam, "Challenges to CoviD-19 vaccine supply chain: Implications for sustainable development goals", International Journal of Production Economics, 239 (2021), 108193.

129 A. David Paltiel, Amy Zheng, Jason L. Schwartz, "Speed versus efficacy: quantifying potential tradeoffs in CoviD-19 vaccine deployment", Annals of internal medicine, 4 (2021), pp. 568-570.

$130 \mathrm{Al} 29$ de octubre de 2021.

131 Heidi J. Larson y David A. Broniatowski, "Volatility of vaccine confidence", Science, 375 (2021), pp. 1289. 


\section{Conclusión}

En este artículo se ha argumentado que, para elucidar el alcance y el significado de la política de las vacunas, además de las agendas gubernamentales y diplomáticas, es necesario examinar su relación y mutua influencia con el desarrollo tecnocientífico. Sin la resistencia de ciudadanos e investigadores, y su labor en la socialización del conocimiento, no sería posible comprender el procesamiento político de la covid-19. La relevancia que adquirió la pandemia en el Norte global, la movilización del ecosistema de innovación biomédica y los cambios en las normas de producción y circulación de conocimiento, posibilitaron los proyectos de vacuna. La competencia internacional y la securitización de los proyectos, la producción y el acceso, afectaron la etapa de desarrollo de las vacunas. A nivel doméstico, las variaciones en los intereses políticos, la autonomía de los reguladores, la actuación de la comunidad científica y la deliberación pública delinearon los procesos de autorización y el resultado de la carrera. La interacción entre la arena política y el desarrollo tecnocientífico dio forma, entre otras posibilidades, a las opciones disponibles para la inmunización internacional y a las controversias sobre seguridad y efectividad que han enmarcado su desarrollo y distribución.

Resultado de esta trayectoria, el arreglo sociotécnico de las vacunas sugiere la formación de tres circuitos para la distribución global. El primero, formado por las vacunas comerciales con alta efectividad, costo y complejidad para el abastecimiento del Norte global y de zonas urbanas en las economías emergentes de mayores ingresos. El segundo, con vacunas asequibles y de menores requerimientos técnicos para su suministro en países en desarrollo, orientadas al avance de las agendas comerciales y políticas de competidores globales emergentes. El tercero, con las vacunas que no logren consolidar una participación sustantiva en el abastecimiento del Norte global, canalizadas a través de covax a los países de bajos ingresos. La estratificación que generarían 
estos circuitos es el núcleo de las controversias sobre el acceso injusto a las vacunas. Sin embargo, este desarrollo no se encuentra determinado. En la sociedad civil, la comunidad científica y las organizaciones internacionales se realiza un escrutinio crítico sobre la actuación de gobiernos y compañías y, en estos grupos, hay iniciativas que buscan el fortalecimiento de covax y la liberación de patentes.

Los hallazgos demuestran que las prácticas de conocer, innovar, gobernar y resistir el poder han estado íntimamente entrelazadas, desde la identificación del sARs-Cov-2 y la configuración de las vacunas, hasta la formación del mercado global. Las implicaciones para investigaciones posteriores son, por lo menos, las siguientes: por un lado, es necesario un escrutinio más detallado sobre el papel del arreglo sociotécnico de las vacunas en el acceso internacional diferenciado y en el diseño de las estrategias de inmunización; por otro lado, es necesario analizar las variaciones en los procesos nacionales de inmunización y sus potenciales impactos en, por ejemplo, la desigualdad, la polarización y los movimientos anticientíficos. Ambas dimensiones son fundamentales para comprender los efectos de retroalimentación y las repercusiones sociopolíticas en el largo plazo.

\section{REFERENCIAS BIBLIOGRÁFICAS}

Abraham, John y Courtney Davis, "Deficits, expectations and paradigms in British and American drug safety assessments: Prising open the black box of regulatory science", Science, technology, E human values, vol. 32 (2007), pp. 399-431.

Alam, Shahriar Tanvir, Sayem Ahmed, Syed Mithun Ali, Sudipa SARker, Golam Kabir y Asif Ul-Islam, "Challenges to Covid-19 vaccine supply chain: Implications for sustainable development goals", International Journal of Production Economics, 239, 2021, 108193. 
Aradau, Claudia y Jef Huysmans, "Critical methods in International Relations: The politics of techniques, devices and acts”, European Journal of International Relations, 20 (2004), pp. 596-619.

Banerjee, Amitava, Suliang Chen, Laura Pasea et al., "Excess deaths in people with cardiovascular diseases during the covid-19 pandemic", European Journal of Preventive Cardiology, 2021, https:/ / doi.org/10.1093/eurjpc/zwaa155

Bar-Zeev, Naor y Tom Inglesby, "Covid-19 vaccines: early success and remaining challenges", The Lancet, vol. 396, 2020, pp. 868-869.

"Biopharma leaders unite to stand with science", AstraZeneca, 8 de septiembre 2020, https://www.astrazeneca.com/content/ astraz/media-centre/press-releases/2020/biopharma-leadersunite-to-stand-with-science.html (consulta del 15 de diciembre de 2020).

Blume, Stuart, "Towards a history of 'the vaccine innovation system' 1950-2000”, en C. Hannaway (ed.), Biomedicine in the twentieth century: Practices, policies, and politics, Holanda, Ios-Press, 2008, pp. 255-286.

Bollyky, Thomas J. y Chad P. Bown, "The tragedy of vaccine nationalism: Only cooperation can end the pandemic", Foreign Affairs, vol. 99, 2020, pp. 96-108.

Briggs, Laura, Reproducing empire: Race, sex, science, and us imperialism in Puerto Rico, Berkeley, University of California Press, 2002.

Buckley, Chris, "Chinese doctor, silenced after warning of outbreak, dies from coronavirus", The New York Times, 7 de febrero 2020, https://www.nytimes.com/2020/02/06/world/asia/ chinese-doctor-Li-Wenliang-coronavirus.html (consulta del 20 de abril de 2021).

Callaway, Ewen, "The unequal scramble for coronavirus vaccinesby the numbers", Nature, vol. 584, 2020, pp. 506-507.

Campbell, Charly, "Exclusive: The Chinese Scientist Who Sequenced the First Covid-19 Genome Speaks Out About the Controversies Surrounding His Work", Time, 24 de agosto de 2020, https: / / time.com/5882918/zhang-yongzhen-interviewchina-coronavirus-genome (consulta del 10 de abril de 2020). 
Carvalho, Simon y Mark Zacher, "The International Health Regulations in Historical Perspective”, en Andrew Price-Smith (ed.), Plagues and politics: infectious disease and international policy, Londres, Palgrave Macmillan, 2001, pp. 235-261.

Chen, Angus, “'We're Racing Time': Biotech Companies Rush To Complete Coronavirus Vaccine”, wBur, 21 de febrero de 2020, https:/ /www.wbur.org/news / 2020/02/21/were-racing-timebiotechnology-companies-rush-to-complete-coronavirus-vac cine (consulta del 12 de diciembre de 2020).

"China begins Phase I trial of covid-19 vaccine", Clinical Trials Arena, 23 de marzo de 2020, https://www.clinicaltrialsarena.com/ news/china-covid-19-vaccine-trial-begins / (consulta del 12 de diciembre de 2020).

"China's Covid-19 vaccine diplomacy steals a march on us", The Financial Times, 12 de noviembre de 2020, https://www.ft.com/ content/ce9a4c98-49b5-4c24-9ff2-ed1c6a3f3412 (consulta del 12 de diciembre de 2020).

Cohen, Jon, “China's vaccine gambit', Science, 370 (6522), 2020, pp. 1263-1267.

"CEPI launches new call for proposals to develop vaccines against novel coronavirus, 2019-nCoV", Coalition for Epidemic Preparedness Innovations (CEPI), 3 de febrero de 2020, https:// cepi.net/news_cepi/cepi-launches-new-call-for-proposals-todevelop-vaccines-against-novel-coronavirus-2019-ncov/ (consulta del 15 de diciembre de 2020).

Cooper, Sam, "China blamed for Canada's multimillion-dollar coronavirus vaccine deal collapse", Global News, 28 de agosto de 2020, https://globalnews.ca/news/7302194/canada-coro navirus-vaccine-deal-china/ (consulta del 10 de diciembre de 2020).

Coronavirus Aid, Relief, and Economic Security Act, Public Law No. 116-136, 134 Stat., 281, 2020,.

"Coronavirus: anger in Germany at report Trump seeking exclusive vaccine deal", The Guardian, 16 de marzo de 2020, https:/ / www.theguardian.com/world/2020/mar/16/not-for-sale-an ger-in-germany-at-report-trump-seeking-exclusive-coronavirusvaccine-deal (consulta del 19 de noviembre de 2020). 
Craven, Jeff, "Covid-19 vaccine tracker", Regulatory Afairs Professionals Society, https://www.raps.org/news-and-articles/newsarticles/2020/3/covid-19-vaccine-tracker (consulta del 15 de febrero de 2021).

Crommelina, Daan J.A., Thomas J. Anchordoquy, David B. Volkin, Wim Jiskoot y Enrico Mastrobattista, "Addressing the cold reality of mRNA vaccine stability", Journal of Pharmaceutical Sciences, 2021, 110 (3), pp. 997-1001.

Cyranoski, David, "What China's coronavirus response can teach the rest of the world", Nature, vol. 579, 2020, pp. 479-481.

Deo, Sahil, Shardul Manurkar, Sanjana Krishnan y Christian Franz, "COVID-19 Vaccine: Development, Access and Distribution in the Indian Context", ORF Issue Brief, vol. 378, 2020,.

Devi, Sharmila, "Us public health budget cuts in the face of covid-19”, The Lancet Infectious Diseases, vol. 20, 2020, p. 415.

DoshI, Peter, "Covid-19 vaccine trial protocols released", $B M J$, vol. 371, 2020, m4058.

Doshi, Peter, "Will covid-19 vaccines save lives? Current trials aren't designed to tell us", BMJ, vol. 371, $2020, \mathrm{~m} 4037$.

Egert, Philip R. y Barbara L. Allen, "Knowledge justice: an opportunity for counter-expertise in security vs. science debates", Science as Culture, vol. 28 (2017), pp. 351-374.

EMANuel, Ezekiel J. et al., "An ethical framework for global vaccine allocation”, Science, vol. 369, 2020, pp. 1309-1312.

EPSTEIN, Steven, Impure science: AIDS, activism, and the politics of knowledge, Berkeley, University of California Press, 1996.

European Commission (EU), COVID-19: EU working on all fronts, €232 million for global efforts to tackle outbreak, Bruselas, CE, 2020.

European Commission (EU), "EU Strategy for COvID-19 vaccines", Bruselas, CE, 2020.

FAZAL, Tanisha M., "Health diplomacy in pandemical times", International Organization, 74, 2020, pp. E78-E97.

Fearnley, Lyle, "Viral Sovereignty or Sequence Etiquette? Asian Science, Open Data, and Knowledge Control in Global Virus Surveillance", East Asian Science, Technology and Society: An International Journal, vol. 14, 2020, pp. 479-505. 
Fidler, David P., "Global health diplomacy and the Ebola outbreak", en Sam Halabi, Lawrence O. Gostin y Jeffrey S. Crowley (eds.), Global Management of Infectious Disease After Ebola, Oxford, University Press, 2017, pp. 133-148.

Fidler, David P., "Vaccine nationalism's politics", Science, vol. 369, 2020 , p. 749.

FidLer, David P., "Influenza virus samples, international law, and global health diplomacy", Emerging infectious diseases, 14, 2008, pp. 88-94.

"French pharma giant Sanofi to give US preference on future covid-19 vaccine", France 24, 13 de mayo de 2020, https:// www.france24.com/en/20200513-french-pharma-giant-sanofito-give-us-preference-on-future-covid-19-vaccine (consulta del 16 de enero de 2021).

Gertner, Jon, "Unlocking the covid Code", The New York Times, 25 de marzo de 2021, https://www.nytimes.com/interactive/ 2021/03/25/magazine/genome-sequencing-covid-variants. html (consulta del 28 de abril de 2021).

Gobierno de la República Popular de China, Ministry of Foreign Affairs of the People's Republic of China, "MFA: China Has Announced Assistance to 82 Countries, wHO and African Union to Fight covid-19", 20 de marzo de 2020, https://www.fmprc. gov.cn/mfa_eng/topics_665678/kjgzbdfyyq/t1759145.shtml (consulta del 12 de diciembre de 2020).

Gobierno del Reino Unido, Department of Health and Social Care, "£20m announced to fund vaccines for coronavirus and other infectious diseases", 3 de febrero de 2020, https://www. gov.uk/government/news/20m-announced-to-fund-vaccinesfor-coronavirus-and-other-infectious-diseases (consulta del 24 de febrero de 2021).

Gostin, Lawrence, "International infectious disease law: revision of the World Health Organization's International Health Regulations", JAMA, vol. 291, 2004, pp. 2623-2627.

Green, Andrew, "Li Wenliang”, The Lancet, vol. 395, 2020.

GutiérRez, Emilio, Jaakko MeriläInen y Adrian Rubli, "Electoral repercussions of a pandemic: evidence from the $2009 \mathrm{H} 1 \mathrm{~N} 1$ Outbreak", ssRn, 2021 (en preprensa). 
Hafner, Marco, Erez Yerushalmi, Clement Fays, Eliane Dufresne y Christian Van STOLK, COVID-19 and the cost of vaccine nationalism, Santa Monica, RAND Corporation, 2020.

HaUray, Boris, "From regulatory knowledge to regulatory decisions: the European evaluation of medicines", Minerva, núm. 55, 2017, pp. 187-208.

Heisbourg, François, "From Wuhan to the world: How the pandemic will Reshape Geopolitics", Survival, vol. 62, 2020, pp. 7-24.

Huzair, Farah y Steve STurdy, "Biotechnology and the transformation of vaccine innovation: The case of the hepatitis B vaccines 1968-2000", Studies in History and Philosophy of Science, vol. 64, 2017, pp. 11-21.

"Jack Ma Commits \$14.4 Million for Coronavirus Vaccine Efforts", PND by Candid, 31 de enero de 2020, Philanthropy News Digest, https:/ / philanthropynewsdigest.org/news/jack-ma-commits-14.4-million-for-coronavirus-vaccine-efforts (consulta del 18 de febrero de 2021).

Jasanoff, Sheila, The Fifth Branch. Science Advisers as Policymakers, Cambridge, Harvard University Press, 1990.

JinPING, Xi, "Fighting Covid-19 Through Solidarity and Cooperation Building a Global Community of Health for All", Virtual Event of Opening of the 73rd World Health Assembly, 18 de mayo de 2020.

Johnson, Raymond M., Peter Doshi y David Healy, "covid-19: Should doctors recommend treatments and vaccines when full data are not publicly available?", BMJ, vol. 370, 2020, m3260.

Johnson, Tana, "Ordinary Patterns in an Extraordinary Crisis: How International Relations Makes Sense of the Covid-19 Pandemic", International Organization, 74, 2020, pp. 148-168.

Joyce, Kelly Ann, Jennifer E. James y Melanie Jeske, "Regimes of Patienthood: Developing an Intersectional Concept to Theorize Illness Experiences", Engaging Science, Technology, and Society, 6, 2020, pp. 185-192.

KIM, Jerome H. et al., "Operation Warp Speed: implications for global vaccine security”, The Lancet Global Health, 2021, núm. 9, pp. 1-5. 
KuPFERSCHMIDT, Kai, "Preprints bring 'firehose' of outbreak data", Science, vol. 367, 2020, pp. 963-964.

Kuriakose, Shinu, "Global health: Global health diplomacy", Journal of Global Health, 10, 2020, 020354.

Lakoff, Andrew, "The Right Patients for the Drug: Pharmaceutical Circuits and the Codification of Illness", en Hackett et al. (eds.), The handbook of science and technology studies, Cambridge, The мiт Press, 2008, pp. 741-759.

LAкоғF, Andrew, "Global health security and the pathogenic imaginary”, en Jasanoff y Kim (eds.), Dreamscapes of modernity: Sociotechnical imaginaries and the fabrication of power, University of Chicago Press, 2015, pp. 300-320.

Larson, Heidi J. y David A. Broniatowski, "Volatility of vaccine confidence", Science, 375, 2021, pp. 1289.

Leese, Matthias y Marijin Hoijtink, "How (not) to talk about technology: international relations and the question of agency", en Hoijtink y Leese (eds.), Technology and agency in international relations, Routledge, 2019, pp. 1-23.

Lezaun, Javier y Catherine M. Montgomery, "The pharmaceutical commons: Sharing and exclusion in global health drug development", Science, Technology, Eॄ Human Values, vol. 40, 2015, pp. 3-29.

Lidskog, Rolf y Göran SundQvist, "When does science matter? International relations meets science and technology studies", Global Environmental Politics, 15, 2015, pp. 1-20.

LiPscy, Phillip Y., "COvid-19 and the Politics of Crisis", International Organization, 74, 2020, pp. E98-E127.

Lipsitch, Marc y Natalie DeAn, "Understanding Covid-19 vaccine efficacy”, Science, vol. 370, 2020, pp. 763-765.

Logunov, Denis Y., Inna V. Dolzhikova, Olga V. Zubkova et al., "Safety and immunogenicity of an rAd26 and rAd5 vectorbased heterologous prime-boost covid-19 vaccine in two formulations: two open, non-randomised phase $1 / 2$ studies from Russia”, The Lancet, vol. 396, 2020, pp. 887-897.

Mallapaty, Smriti y Heidi LedFord, "COvid-vaccine results are on the way-and scientists' concerns are growing", Nature, vol. 586, 2020, pp. 16-17. 
MamoA, Laura y Steven EPSTEIn, “The pharmaceuticalization of sexual risk: vaccine development and the new politics of cancer prevention”, Social Science E Medicine, vol. 101, 2014, pp. 155-165.

Mayer, Maximilian, Mariana Carpes y Ruth Knoblich (eds.), The Global Politics of Science and Technology, Suiza, Springer-Verlag, 2014, pp. 1-35.

McNamara, Kathleen R. y Abraham L. Newman, "The Big Reveal: COVID-19 and Globalization's Great Transformations", International Organization, vol. 74, 2020, pp. 59-77.

Molter, Vanessa y Renee DiResta, "Pandemics \& propaganda: how Chinese state media creates and propagates CCP coronavirus narratives", Harvard Kennedy School Misinformation Review, 2020, 1 (3).

Murphy, Flynn, "Inside China's Response to Covid", Nature, vol. 588, 2020, pp. S49-S51.

OrsinI, Amandine, et al., "Boundary concepts for boundary work between science and technology studies and international relations: Special issue introduction", Review of Policy Research, 34, 2017, pp. 734-743.

Oxfam International, "Small group of rich nations have bought up more than half the future supply of leading Covid-19 vaccine contenders", 17 de septiembre de 2020, https://www.oxfam. org/en/press-releases/small-group-rich-nations-have-boughtmore-half-future-supply-leading-covid-19

Paltiel, A. David, Amy Zheng, Jason L. Schwartz, "Speed versus efficacy: quantifying potential tradeoffs in covid-19 vaccine deployment", Annals of internal medicine, 4, 2021, pp. 568-570.

Petryna, Adriana, When experiments travel: clinical trials and the global search for human subjects, Princeton, University Press, 2009.

Phelps, Jordyn y Karen Travers, "Trump not concerned China may be covering up full extent of coronavirus outbreak", ABC News, 7 de febrero de 2020, https://abcnews.go.com/Politics/trump-concerned-china-covering-full-extent-coronavirusoutbreak/story?id=68824019 (consulta del 19 de noviembre de 2020). 
Philipe, Edouard, Twitter, @EPhilippe_LH, 14 de mayo de 2020, https://twitter.com/EPhilippe_LH/status/126088656070425 8048 ?s=20 (consulta del 16 de enero de 2021).

Phillips, Nicky, et al., "A leading coronavirus vaccine trial is on hold: scientists react”, Nature, 9 de septiembre de 2020, https:/ / www.nature.com/articles/d41586-020-02594-w (consulta del 25 de enero de 2021).

Pubmed, https:/ / pubmed.ncbi.nlm.nih.gov/ (consulta del 20 de abril de 2021). “¿Qué pasará con la ue tras el covid-19?”, $L a$ Vanguardia, 30 de marzo de 2020, https://www.lavanguardia. com/participacion/debates/20200330/48160119733/debatefuturo-union-europea-crisis-coronavirus-covid-19-brexit.html (consulta del 15 de diciembre de 2020).

Robins, Rebecca, Sharon LaFraniere, Noah Weiland, David D. KirkPATrick y Benjamin Mueller, "Blunders Eroded U.s. Confidence in Early Vaccine Front-Runner", The New York Times, 8 de diciembre de 2020, https:/ / www.nytimes.com/2020/12/08/ business/covid-vaccine-oxford-astrazeneca.html (consulta del 18 de diciembre de 2020).

Rogoża, Jadwiga y Iwona Wiśniewska, "Russia in the global "vaccine race'”, OSW Commentary, núm. 358, 2020.

Rourke, Michelle, "Restricting access to pathogen samples and epidemiological data: a not-so-brief history of "viral sovereignty' and the mark it left on the world", en Eccleston-Turner y Brassington (eds.), Infectious Diseases in the New Millennium, Springer International Publishing, 2020, pp. 167-191.

Santos Rutschman, Ana, "The reemergence of vaccine nationalism”, Georgetown Journal of International Affairs, 2020 (en preprensa).

"Sharing research data and findings relevant to the novel coronavirus (covid-19) outbreak", Wellcome, 31 de enero de 2020, https://wellcome.org/coronavirus-covid-19/open-data (consulta del 19 de marzo de 2021).

SHiн, Gerry, "In coronavirus outbreak, China's leaders scramble to avert a Chernobyl moment", 29 de enero de 2020, https:// www.washingtonpost.com/world/asia_pacific/in-coronavirusoutbreak-chinas-leaders-scramble-to-avert-a-chernobyl-mo 
ment/2020/01/29/bc4eb52a-4250-11ea-99c7-1dfd4241a2fe story.html (consulta del 24 de abril de 2021).

Shrotri, Madhumita, Tui Swinnen, Beate Kampmann y Edward P. K. PARKER, "An interactive website tracking COVID-19 vaccine development”, Lancet Global Health, vol. 9, 2021, pp. 590-592.

Soiza, Roy L., Chiara Scicluna y Emma C. Thomson, "Efficacy and safety of COVID-19 vaccines in older people", Age and Ageing, vol. 50, 2021, pp. 279-283.

Steenhuysen, Julie, "J\&J, Moderna sign deals with U.s. to produce huge quantity of possible coronavirus vaccines", Reuters, 30 de marzo de 2020, https://www.reuters.com/article/us-healthcoronavirus-johnson-johnson-idUSKBN21H1OY (consulta del 9 de diciembre 2020).

The Independent Panel for Pandemic Preparedness and Response, Second Report on Progress, World Health Organization, 2021.

The White House, "Remarks by President Trump and Vice President Pence in Roundtable with Industry Executives on the Plan for Opening Up America Again”, 29 de abril de 2020, https:/ / trumpwhitehouse.archives.gov/briefings-statements/remarkspresident-trump-vice-president-pence-roundtable-industry-ex ecutives-plan-opening-america/ (consulta del 23 de noviembre de 2020).

The White House, "Remarks by President Trump at Signing of a Proclamation in Honor of National Nurses Day", 6 de mayo de 2020, https://trumpwhitehouse.archives.gov/briefings-state ments/remarks-president-trump-signing-proclamation-honornational-nurses-day/ (consulta del 24 de noviembre de 2020).

The White House, "Remarks by President Trump on Vaccine Development”, 15 de mayo de 2020, https://trumpwhitehouse.archi ves.gov/briefings-statements/remarks-president-trump-vac cine-development/ (consulta del 17 de diciembre de 2020).

"The Wuhan Lab Theory", The Wall Street Journal, 6 de mayo de 2020, https:/ / www.wsj.com/articles/the-wuhan-lab-theory-1158880 6940 (consulta del 22 de noviembre de 2020).

Towghi, Fouzieyha, "The biopolitics of reproductive technologies beyond the clinic: localizing HPV vaccines in India", Medical Anthropology, vol. 32 (2013), pp. 325-342. 
"Transcript: ABC News anchor David Muir interviews President Trump in Arizona”, Авс News, 6 de abril de 2020, https:/ / abcnews.go.com/Politics/transcript-abc-news-anchor-davidmuir-interviews-president/story?id=70523003 (consulta del 22 de noviembre de 2020).

Trouiller, Patrice, Piero Olliaro, Els Torreele, James OrbinsKI, Richard LAING y Nathan ForD, "Drug development for neglected diseases: a deficient market and a public-health policy failure", The Lancet, vol. 359, 2002, pp. 2188-2194.

Trump, Donald, Twitter, 22 de agosto de 2020, @realDonaldTrump, https://twitter.com/realDonaldTrump/status/129713886210 8663808 (consulta del 17 de noviembre de 2020).

"Trumping science”, Nature Biotechnology, 38, 2020, pp. 1105, https:/ / doi.org/10.1038/s41587-020-0713-y

University of Oxford y Global Change Data Lab, "Coronavirus (covid-19) Vaccinations", Our World in Data, https://ourworldindata.org/covid-vaccinations (consulta del 19 de febrero de 2021).

VArgina, Valeria, "Sputnik V Vaccine as a Soft-Power Instrument of Russia”, Journal of Governance and Politics, 2020, 2 (7), (en preprensa).

Verma, Raj, "China's 'mask diplomacy'to change the COVID-19 narrative in Europe", Asia Europe Journal, vol. 18, 2020, pp. 205-209.

Walker, Joseph y Jenny Strasburg, "AstraZeneca Defends Dosing Error in COvid-19 Vaccine Trial”, 25 de diciembre de 2020, https://www.wsj.com/articles/astrazeneca-defends-dosing-error-in-covid-19-vaccine-trial-11606358805 (consulta del 8 de febrero de 2021).

Warren, Rueben C., Lachlan Forrow, David Augustin Hodge, Sr. y Robert D. TruOG, "Trustworthiness before Trust - COVID-19 vaccine trials and the Black community", New England Journal of Medicine, vol. 383, 2021, e121.

World Health Organization (wHO), Pandemic influenza preparedness framework for the sharing of influenza viruses and access to vaccines and other benefits, Francia, wHO, 2011.

World Health Organization (wHo), International Health Regulations (2005), Third Edition, wHo, 2016. 
World Health Organization (wHO), "Listings of wHO's response to COviD-19”, 29 de junio de 2020, https://www.who.int/news/ item/29-06-2020-covidtimeline (consulta del 14 de octubre de 2020).

World Health Organization (wHo), A Coordinated Global Research Map, Geneva, wHo, 2020.

World Health Organization (wHo), What is the Access to COVID-19 Tools (ACT) Accelerator, how is it structured and how does it work?, Switzerland, wHo, 2021.

World Health Organization (WHO), COVID-19 vaccination: supply and logistics guidance: interim guidance, wHO, 2021.

"Whoever Finds the Vaccine Must Share It": Strengthening Human Rights and Transparency Around COVID-19 Vaccines, Human Rights Watch, 2020.

Whoriskey, Peter y Neena Satija, "How u.s. coronavirus testing stalled: Flawed tests, red tape and resistance to using the millions of tests produced by the wHo", The Washington Post, 16 de marzo de 2020, https://www.washingtonpost.com/business/ 2020/03/16/cdc-who-coronavirus-tests/ (consulta del 4 de diciembre de 2020).

Woolston, Chris, “'I've never worked harder': the race to develop a covid-19 vaccine”, Nature, vol. 587, 2020, pp. 322-322.

Wu, Katherine J., "Safety Review Underway of AstraZeneca's Vaccine Trial", The New York Times, 10 de septiembre de 2020, https:/ / www.nytimes.com/2020/09/10/health/covid-astra zeneca-vaccine-trans.html (consulta del 7 de febrero de 2021). "Six-episode large-scale documentary: Fighting with the Epidemic", Xinhua News Agency, 31 de agosto de 2020, http://www.xhby. net/tuijian/202008/t20200831_6785354.shtml (consulta del 11 de marzo de 2021).

Youde, Jeremy, "MERs and global health governance", International Journal, vol. 70 (2015), pp. 119-136.

ZainI, Khairulanwar, "China's Vaccine Diplomacy in Southeast Asia-A Mixed Record”, ISEAS Perspective 2021, núm. 86, 2021. 
